\title{
REVIEW
}

\section{High-rate lithium ion energy storage to facilitate increased penetration of photovoltaic systems in electricity grids}

\begin{abstract}
Alison Lennon, Yu Jiang, Charles Hall, Derwin Lau and Ning Song, School of Photovoltaic and Renewable Energy Engineering, UNSW Sydney, NSW 2052, Australia

Patrick Burr, School of Mechanical and Manufacturing Engineering, UNSW Sydney, NSW 2052, Australia

Clare P. Grey, Department of Chemistry, University of Cambridge, Cambridge CB2 1EW, U.K.

Kent J. Griffith, Department of Chemistry, University of Cambridge, Cambridge CB2 1EW, U.K.; and Department of Materials Science and Engineering, Northwestern University, Evanston, Illinois 60208, USA

Address all correspondence to Alison Lennon at a.lennon@unsw.edu.au (Received 10 May 2018; accepted 21 February 2019)
\end{abstract}

\section{ABSTRACT}

High-rate lithium ion batteries with long cycling lives can provide electricity grid stabilization services in the presence of large fractions of intermittent generators, such as photovoltaics. Engineering for high rate and long cycle life requires an appropriate selection of materials for both electrode and electrolyte and an understanding of how these materials degrade with use. High-rate lithium ion batteries can also facilitate faster charging of electric vehicles and provide higher energy density alternatives to supercapacitors in mass transport applications.

High-rate lithium ion batteries can play a critical role in decarbonizing our energy systems both through their underpinning of the transition to use renewable energy resources, such as photovoltaics, and electrification of transport. Their ability to be rapidly and frequently charged and discharged can enable this energy storage technology to play a key role in stabilizing future low-carbon electricity networks which integrate large fractions of intermittent renewable energy generators. This decarbonizing transition will require lithium ion technology to provide increased power and longer cycle lives at reduced cost. Rate performance and cycle life are ultimately limited by the materials used and the kinetics associated with the charge transfer reactions and ionic and electronic conduction. We review material strategies for electrode materials and electrolytes that can facilitate high rates and long cycle lives and discuss the important issues of cost, resource availability and recycling.

Keywords: energy storage; photovoltaic; energy generation; Li; sustainability

\section{DISCUSSION POINT}

- In our review, we consider the important contribution that electrochemical energy storage, and in particular lithium ion batteries, can make to increase the stability and reliability of electricity grids in the presence of high fractions of renewable energy generators and, in particular, photovoltaics. Unlike other energy storage applications, where energy density may be paramount, we propose that for the electricity grid stabilization functionality what is important is high rate and long cycle life. The attributes of high rate and long cycle life are also required for increased electric vehicle adoption. Material strategies that may be able to address these requirements are critically reviewed and an assessment is provided of economic considerations and resourcing problems that may be incurred with large volume battery manufacturing for renewable energy integration into electricity grids. 


\section{Introduction}

In an 1883 interview, Thomas Edison said of energy storage ${ }^{1}$ :

"Scientifically, storage is all right, but, commercially, as absolute a failure as one can imagine. You can store it and hold it, but it is gradually lost, and will all go in time. Its efficiency, after a certain number of charges have been sustained, begins to diminish, and its capacity and efficiency both diminish after a certain time in use, necessitating an increased number of batteries to maintain a constant output."

More than 130 years on, electrochemical energy storage is now poised to play a critical role in decarbonizing our energy systems, both through its underpinning of the transition to use renewable energy resources, such as photovoltaics (PV), and its central role in electrification of transport. ${ }^{2}$ Although, to-date, battery technology development has been driven by the miniaturization of mobile electronics and, more recently, energy storage for electric vehicles $(\mathrm{EVs})$, it is becoming increasingly important to consider also its role in electricity generation from low-carbon energy resources. Without widescale replacement of fossil fuels with near-zero carbon energy sources for electricity generation, the life cycle emission damages that result from battery production and charging can be greater for plug-in hybrid and full-battery EVs than for hybrid EVs due to the emissions from coal-fired power plants used for electricity generation. ${ }^{3,4}$

$\mathrm{PV}$ is the fastest growing renewable energy technology (40\% per year over the last decade $\left.{ }^{5-7}\right)$ and has the fastest manufacturing experience (learning) rate of all renewable energy technologies $\left(22.8 \%\right.$ over the past 40 years $\left.^{8}\right)$. By 2050 , PV could supply $30-50 \%$ of the world's electricity, with the levelized cost of electricity from PV expected to be in the range of US\$0.02-\$0.06/kWh. ${ }^{7}$ Especially for regions in the "sun belt" (see Fig. 1), PV provides a valuable and cost-effective means to contribute to the decarbonization of the electricity sector, especially if part of a mix of near-zero carbon electricity generators. ${ }^{7,9-11}$ Unlike fossil fuel resources, solar energy is ubiquitous, and so once a PV system has been installed, the price of the electricity generated is predictable and not subject to resource pricing changes. ${ }^{12}$ This can provide a global energy stability that has not previously been possible with energy systems that rely on resources distributed unevenly across the world. ${ }^{2}$

The energy storage attributes required to facilitate increased integration of PV in electricity grids are not generally well understood. While load shifting and peak shaving of residential PV generation ${ }^{13-17}$ may be achieved using batteries with relatively low power rates, power generation from solar PV can change unpredictably on sub-second time scales ${ }^{18-22}$ and destabilize electricity networks. In the absence of technological solutions, this unpredictable intermittence can limit penetration levels of PV and indeed also other intermittent resources, such as wind. However, there is another view that use of wind and PV in concert with parallel grid-forming inverters ${ }^{23-26}$ and rapidly responding frequency stabilization services that utilize energy storage ${ }^{17,22,27-33}$ can enable more flexible and resilient electricity grids. ${ }^{2,17}$ With the rapid reduction in costs of PV that are occurring, reduced and sustainable electricity prices may be possible and the full advantages of transport electrification can be realized.

Lithium ion batteries (LIBs) ${ }^{34-36}$ have been identified as the most promising option for high-rate energy storage (i.e., fast charging and high power) at acceptable cost. ${ }^{22,30,33,35,37-41}$ In a comparison of the ability of selected electrochemical energy storage technologies to maintain the inherent power fluctuations of PV systems to within acceptable ramp rates of $<10 \% / \mathrm{min}$, Jiang et al. found that high-rate LIBs required a smaller battery volume compared to other energy storage technologies when high compliance levels were required. ${ }^{22}$ For the particular case of a 7.2 MW PV system (covering an area of $52 \mathrm{Ha}$ ), use of a high-rate LIB required only $\sim 40 \%$ and $\sim 4 \%$ of the volume of a high-energy LIB and a lead acid battery, respectively, to maintain the ramp rate within $<10 \% /$ min with $99 \%$ compliance (see Fig. S1). This significantly reduced volume, taken together with the longer cycle life of the high-power LIB $\left(>10^{4}\right.$ compared with $<1000$ cycles for the high-energy density LIB and the lead acid battery), suggests the potential for lower "service" costs, or costs per cycle, of high-power LIBs with long cycle lives compared to other alternatives. High-power LIBs can also allow faster charging of EVs, thereby promoting greater adoption of consumer EVs. ${ }^{36,42}$

Although economically competitive, cost-per-cycle services will require the design and engineering of battery modules (from cells), and associated thermal and power management systems, rate performance, and cycle life are ultimately limited by the materials used in cells and the kinetics associated with the charge transfer reactions and ionic and electronic conduction. The requirement of long cycling life, which necessitates that parasitic side reactions are minimized, will be critical for the cost-effectiveness of LIB solutions for future flexible electrical power systems due to the need for rapid charging/discharging on a much more frequent basis than expected for most other LIB applications (e.g., EVs, residential storage, and portable electronics). This paper first reviews technological strategies that can be used to enhance the rate capability of LIBs; then subsequent sections discuss the projected costs of LIBs, the resource availability and recycling that would be required for high-volume manufacturing of LIBs to support high penetration levels of PV generation.

\section{LIB technology}

LIBs are based on the "rocking-chair" concept introduced by Armand and others in the $1970 \mathrm{~s}^{36,43}$ The cell technology (see Fig. 2), which was first commercialized by Sony in the $1990 \mathrm{~s},{ }^{34-36}$ comprises a graphite anode, a layered metal oxide intercalation cathode, and an electrolyte comprising a Li ion salt dissolved in organic liquid. Commercially produced LIBs can achieve 


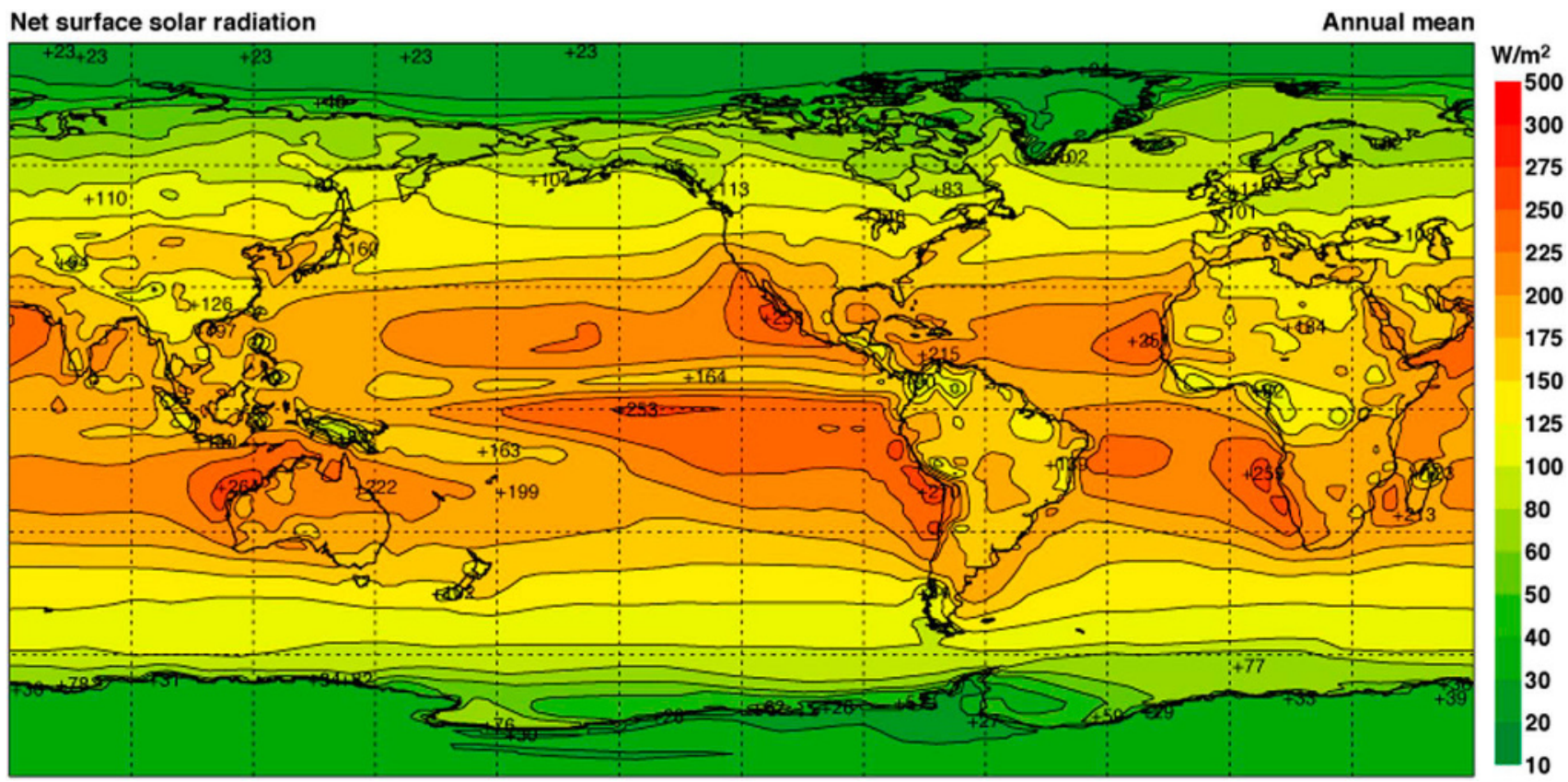

Figure 1. Map of annual mean net surface solar radiation. The differences in solar radiation over different regional areas are highlighted with a color gradient (reproduced from ECMWF; available at https://software.ecmwf.int/static/ERA-40_Atlas/docs/section_B/parameter_nsfosrpd.html).

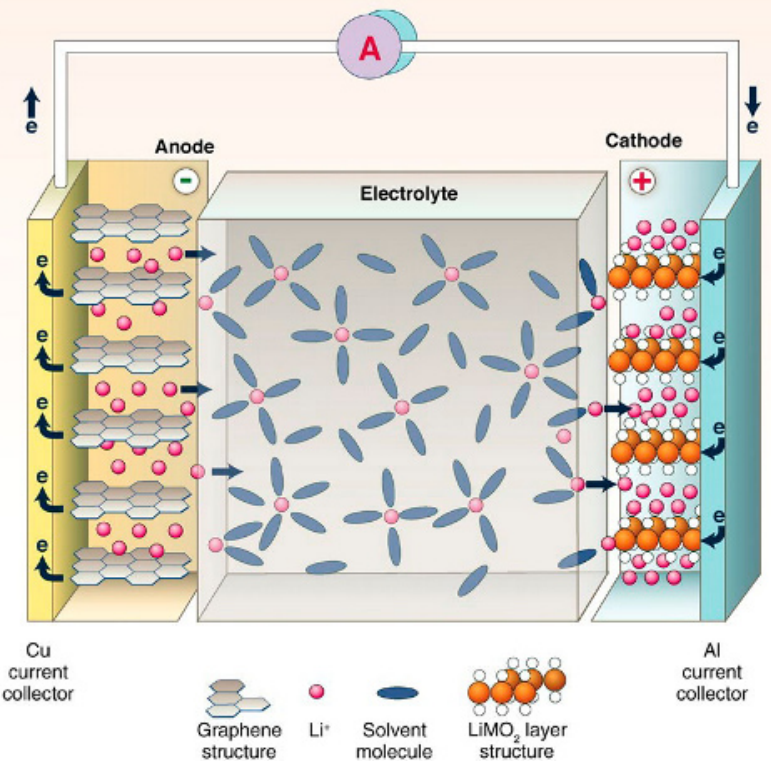

Figure 2. Schematic diagram of an intercalation Li ion rechargeable battery. Most commercially produced LIBs comprise a graphite anode, a metal oxide cathode (e.g., LCO, LMO, NCA, and NMC), and an organic electrolyte with a Li ion salt (from Dunn et al. ${ }^{37}$ and reprinted with permission from AAAS).

volumetric energy densities exceeding $770 \mathrm{Wh} / \mathrm{L},{ }^{44}$ allowing for driving ranges of more than $500 \mathrm{~km}$ (Tesla Model S P100D, Tesla, Fremont, California). Power densities for these cells tend to be limited to $<1 \mathrm{~kW} / \mathrm{L}$, but new high-power 21700 -format cells may be able to push this toward $1.5+\mathrm{kW} / \mathrm{L} .{ }^{45}$ Limitations to charging/discharging rates can arise from anode and cathode materials, electrolyte selection, and fabrication process.

The low lithiation potential of graphite $\left(\sim 0.1\right.$ versus $\left.\mathrm{Li}^{+} / \mathrm{Li}\right)$ results in the formation of a solid electrolyte interphase (SEI) at the graphite surface due to the reductive decomposition of electrolyte species at low potentials. ${ }^{46-48}$ The SEI electronically passivates the graphite anode but still allows the transport of $\mathrm{Li}$ ions to the electrode surface on charging; however, ionic transport is partially restricted by the SEI, which limits charging rates. The continued growth of the SEI during cycling, especially at high charging rates ${ }^{49}$ limits the number of times the battery can be cycled. Additionally, at high rates, Li has a propensity to "plate" on the graphite electrode, resulting in Li dendrites that propagate through the separator and cause short circuits, leading to thermal runaway and fires. ${ }^{50-55}$ These limitations are exacerbated at high rates due to large Li-ion concentration overpotentials ${ }^{49,56,57}$ that can evolve as the ions diffuse along the tortuous pathways presented by the flake-like graphite particles of electrodes. ${ }^{58}$

There have been numerous developments since the 1990s in layered metal oxide intercalation cathode materials, especially with regard to increased capacity and/or voltage, both design attributes leading to increased energy density. ${ }^{59,60}$ Cathode materials used in commercially produced LIBs include $\mathrm{LiCoO}_{2}$ (LCO), $\mathrm{LiMn}_{2} \mathrm{O}_{4}$ (LMO), $\mathrm{LiFePO}_{4}$ (LFP), $\mathrm{LiNi}_{0.8} \mathrm{Co}_{0.15} \mathrm{Al}_{0.05} \mathrm{O}_{2}$ (NCA), and $\mathrm{LiNi}_{x} \mathrm{Mn}_{y} \mathrm{Co}_{1-x-y} \mathrm{O}_{2}$ (NMC). Although typically LIB cathodes are not rate limiting, use of higher charging rates can result in significant reductions in capacity and increased battery impedance. ${ }^{55,61}$ 


\section{Technological design strategies}

The key advantage of LIBs for high-rate applications lies is the fast diffusion rates of $\mathrm{Li}$ in electrode materials combined with its low mass and high electronegativity, allowing for high gravimetric and volumetric energy and power densities. ${ }^{62}$ Although the rate capabilities of battery cells are best discussed in terms of the specific gravimetric and/or volumetric power and energy densities which take into account the mass/volume of all components of the entire cell, the rate capability of electrode materials is useful to report and consider in terms of capacity and cyclability at comparative C-rates or current densities with appropriate consideration for areal loading and active material content. The C-rate is the rate at which an electrode (or device) is discharged relative to its theoretical capacity [e.g., a $1 \mathrm{C}$ rate means that the (dis)charge current will fully (dis)charge an electrode or device in $1 \mathrm{~h}$; 10C is 10 (dis)charges per hour or 6 min per complete (dis)charge]. The term "high-rate" is often used without a clear definition; however, for this article, we assume that it applies to batteries that can be operated with a C-rate exceeding $1 \mathrm{C}$, which is consistent with the definition used by Eftekhari, ${ }^{63}$ and is a reasonable definition for large-scale applications, such as grid scale and EVs, though we acknowledge that high-rate is a relative term and a value of $5 \mathrm{C}-10 \mathrm{C}$ may be more appropriate for smaller battery cells in portable devices with more manageable strategies for heat generation.

\section{Electrode materials}

Since dendritic growth of $\mathrm{Li}$ on graphite anodes is enhanced at larger current densities, ${ }^{64,65}$ high-rate LIBs tend to use anode materials that can be cycled at higher potentials for increased safety. Crystalline materials on the binary $\mathrm{Li}_{2} \mathrm{O}-\mathrm{TiO}_{2}$ composition line [e.g., the spinel form $\mathrm{Li}_{4} \mathrm{Ti}_{5} \mathrm{O}_{12}$ (LTO ${ }^{66-68}$ ] have been used as an alternative anode material for high-rate LIBs due to their higher $\mathrm{Li}$ ion insertion potential of $\sim 1.5 \mathrm{~V}$ versus $\mathrm{Li}^{+} / \mathrm{Li}^{69-71}$ Although the higher reaction potential decreases the energy density of the battery and in doing so increases the cost per kilowatt hour stored, it diminishes the risk of Li plating and dendrite formation during cycling at high rates. Additionally, electrolyte decomposition is thermodynamically less favorable at the higher voltages. This minimizes SEI formation and reduces impedance on charging/discharging thus improving rate capability. The higher voltage also permits the use of the $\mathrm{Al}$ as a current collector (which is lighter and cheaper than $\mathrm{Cu}$ ) as $\mathrm{Li}$ alloying with $\mathrm{Al}$ does not occur until $0.3 \mathrm{~V}$ versus $\mathrm{Li}^{+} / \mathrm{Li}^{72}$

Spinel LTO has an excellent cycle life due to its thermal stability and negligible volume change on cycling. ${ }^{56,68,70}$ It was the first commercialized non-carbonaceous anode material for LIBs, with Toshiba and Altairnano employing anodes comprising micrometer-sized secondary LTO particles for higher rates and longer cycle lives in their higher rate LIB products, which have achieved power densities of $4 \mathrm{~kW} / \mathrm{kg}(6.5 \mathrm{~kW} / \mathrm{L}){ }^{73-76}$ However, the specific reversible capacity of LTO electrodes is limited to less than $175 \mathrm{mAh} / \mathrm{g}\left(\mathrm{Li}_{4+}{ }_{x} \mathrm{Ti}_{5} \mathrm{O}_{12}, 0 \leq x \leq 3\right),{ }^{70,77}$ with its charging/discharging rate being limited by the poor conductivity of the micrometer-sized particles used in the electrodes. ${ }^{67}$
In recent years, these issues have been addressed through use of C-coating and nanostructuring, allowing LTO capacities exceeding $150 \mathrm{mAh} / \mathrm{g}$ to be achieved at rates of $10 \mathrm{C}^{78,79}$; however, these strategies negatively impact the volumetric capacity and may not be commercially viable for some applications.

Various crystalline $\mathrm{TiO}_{2}$ polymorphs have also been explored as alternatives to LTO. Fully lithiated $\mathrm{TiO}_{2}$ (i.e., $\mathrm{LiTiO}_{2}$ corresponding to $100 \%$ reduction of $\mathrm{Ti}^{4+}$ to $\mathrm{Ti}^{3+}$ on lithiation) has a theoretical capacity of $335 \mathrm{mAh} / \mathrm{g}$, which is only slightly less than that of graphite $(372 \mathrm{mAh} / \mathrm{g})$. Among the many crystalline $\mathrm{TiO}_{2}$ polymorphs reported, rutile, anatase, brookite, and the "bronze" form $\mathrm{TiO}_{2}-\mathrm{B}^{80}$ have been shown to have Li electrochemical activity, and all have theoretical volumetric capacities that significantly exceed that of LTO (see Table S1). ${ }^{70}$ However, full lithiation of these $\mathrm{TiO}_{2}$ polymorphs can only be approached using nanostructures, ${ }^{70,71,81,82}$ and it has been largely through the study of nanostructured $\mathrm{TiO}_{2}$ polymorphs that differences in Li ion charging/discharging rates and capacities arising from crystal structure have been observed. Of particular interest, has been the high rate and cycle life reported for the bronze polymorph $\mathrm{TiO}_{2}-\mathrm{B} .{ }^{70,83-86}$ The faster charge storage reported for this form has been attributed to freely accessible parallel channels for Li ion transport perpendicular to the $(010)$ face $^{83}$ in the relatively open bronze polymorph. ${ }^{70}$

Another strategy for increasing the energy density of Ti-based anodes without significantly compromising their rate capability is to incorporate additional transition metals. ${ }^{87-93}$ Higher capacities are theoretically possible, especially if the valence of the added metal can change by more than one (e.g., through use of Mo, W, V, and Nb). The addition of heavier metals may not necessarily increase the specific energy density of the resulting cells; ${ }^{61}$ it is more likely to lead to gains in volumetric performance. Of particular interest has been the family of $\mathrm{TiO}_{2}-\mathrm{Nb}_{2} \mathrm{O}_{5}$ (TNO) materials due to their high theoretical capacity (up to $400 \mathrm{mAh} / \mathrm{g}$ with multielectron redox; see Table S1) arising from the idealized $\mathrm{Ti}^{4+} / \mathrm{Ti}^{3+}$ and $\mathrm{Nb}^{5+} / \mathrm{Nb}^{3+}$ redox couples. ${ }^{87,88,92-94}$ Toshiba have adopted this strategy in their high-power SciB cells, which employ a $\mathrm{TiNb}_{2} \mathrm{O}_{7}$ anode comprising C-coated micrometer-sized particles and an $\mathrm{LiNi}_{0.6} \mathrm{Co}_{0.2} \mathrm{Mn}_{0.2} \mathrm{O}_{2}$ (NCM) cathode to achieve power and energy densities of $10 \mathrm{~kW} / \mathrm{L}$ (charging for $10 \mathrm{~s}$ at $50 \%$ state of charge) and $\sim 350 \mathrm{Wh} / \mathrm{L}$, respectively. ${ }^{93}$ Although this energy density surpasses that of similar cells with LTO anodes $(177 \mathrm{Wh} / \mathrm{L}),{ }^{40}$ it is still only half that possible with state-of-the-art high-energy density cells.

This approach of using open structural motifs can present advantages over nanostructuring in achieving higher rate electrodes without compromising capacity because volumetric energy density is not reduced due to pore volume (i.e., they have greater tap density). Griffith et al. adopted this approach with $\mathrm{Nb}_{x} \mathrm{~W}_{y} \mathrm{O}_{z} 3 \mathrm{D}$ open lattice structures. The multielectron redox capabilities of both $\mathrm{Nb}^{5+}$ and $\mathrm{W}^{6+}$ lead to theoretical capacities for $\mathrm{Nb}_{x} \mathrm{~W}_{y} \mathrm{O}_{z}$ compounds of $300-400 \mathrm{mAh} / \mathrm{g}$ ( similar to the titanium niobium oxides); however it remains open as to whether full two electron redox will be accessible under stable cycling conditions (especially at high rates) even though multielectron is achievable in both individual metal oxide families. With electrodes 
comprising $\mathrm{Nb}_{18} \mathrm{~W}_{16} \mathrm{O}_{93}$ micrometer-sized solid particles, capacities of $\sim 150 \mathrm{mAh} / \mathrm{g}$ at $10 \mathrm{C}$ and $\sim 75 \mathrm{mAh} / \mathrm{g}$ at $100 \mathrm{C}$ were realized (see Fig. 3). ${ }^{95}$ Nanostructuring or the use of amorphous forms of mixed metal oxides ${ }^{96}$ may provide paths to further increases in (gravimetric) capacity for these multiple transition metal anode materials.

Although this discussion has focused more on anode materials due to the need to find alternative safe anode materials for high-rate devices, achievement of high rate in cells requires that the $\mathrm{Li}$ insertion and extraction processes and electron transport are rapid in both the anode and cathode materials. Currently, most cathode materials are limited by the conduction of Li ions in the crystalline cathode material. Consequently, large concentration overpotentials occur at high lithiation rates, resulting in electrolyte oxidation, dissolution of cathode materials, and corrosion of the current collector. ${ }^{50,97}$ Metals released by cathode oxidative decomposition can diffuse through the electrolyte to deposit on the anode and/or contribute to SEI growth and further degrade battery performance. ${ }^{55,61}$ Collectively, these aging mechanisms result in increased impedance and reduced cycle life of the battery and may necessitate a narrowed cycling voltage (thus smaller utilized capacity) to be used for high-rate operation. The material strategies that have been discussed above could also be applied to the engineering of high-rate cathode materials, although additional research is required to understand the electrode degradation mechanisms with high rate usage at high oxidation potentials.

The rate capability of both anode and cathode materials can also be enhanced through the use of carbon coating and nanosizing. An often-quoted example of the value of carbon coating is the story of $\mathrm{FePO}_{4}$, a material that was initially considered to be a low-rate cathode material due the poor electronic conductivity of both oxidized and reduced forms and poor ionic conductivity of micron-size particles. ${ }^{98,99}$ The use of nanomaterials decreases both the Li and electron transport lengths. Additionally it reduces the probability that Fe antisite defects block ion transport in the 1D tunnels (aligned in the [010] crystallographic direction). It was found that the rate of charging/discharging these electrodes a)

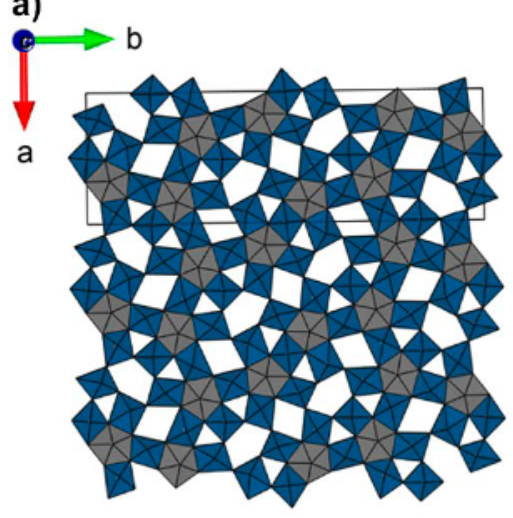

d)

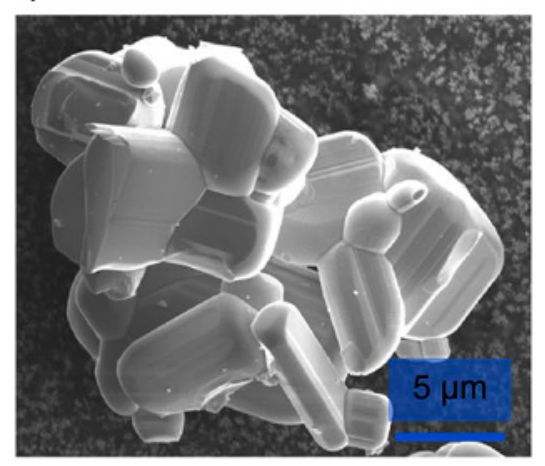

b)

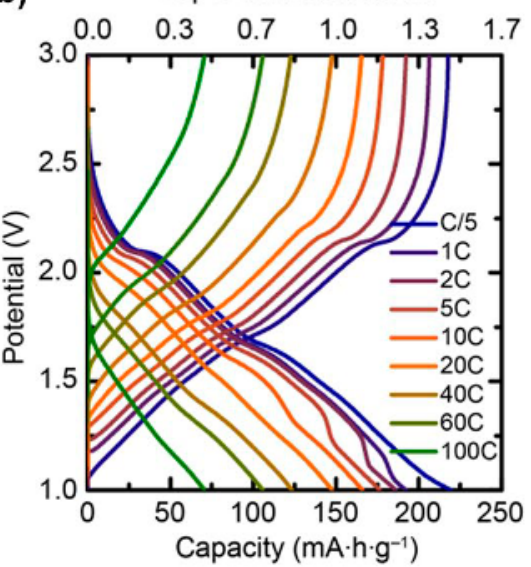

e)

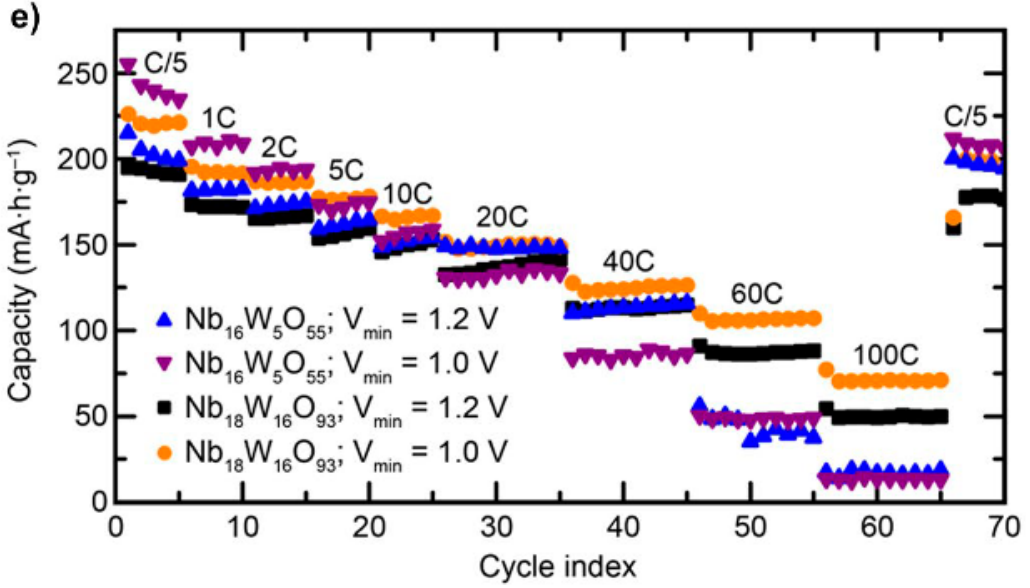

Figure 3. Structure of the bronze-like $\mathrm{Nb}_{18} \mathrm{~W}_{16} \mathrm{O}_{93}$. (a) Crystallographic structure of the bronze-like $\mathrm{Nb}_{18} \mathrm{~W}_{16} \mathrm{O}_{93}$ showing open the structural motif that facilitates fast Li ion diffusion through the lattice, (b) electrochemical voltage profiles as a function of lithium concentration and C-rate, (c) derivative curve of the voltage profiles, (d) electron microscope image showing the micrometer-sized particles of the mixed metal oxide, and (e) gravimetric capacity as a function of C-rate for two different $\mathrm{Nb}_{x} \mathrm{~W}_{y} \mathrm{O}_{z}$ materials and cycling limits (reproduced with permission from Griffith et al. ${ }^{95}$ ). 
was also dependent on the $\mathrm{Li}$ ion transport across the surface of the particles as the ions can only move into the bulk of the crystalline $\mathrm{FePO}_{4}$ in 1D channels. ${ }^{99-101}$ By carbon coating the surfaces of the particles, charging capacity was significantly increased. ${ }^{102,103}$ Herle et al. proposed that the increased rate capability was due to the formation of a highly conductive surface layer of iron phosphide (FeP) arising from the carbothermal reduction of $\mathrm{Fe}$ at C-contaminated $\mathrm{FePO}_{4}$ surfaces. ${ }^{104} \mathrm{Kang}$ and Ceder reported the fabrication of a conductive $\mathrm{Li}_{4} \mathrm{P}_{2} \mathrm{O}_{7}$-like amorphous phase on the surface of the particles using a heat treatment to improve the rate capability of LFP cathodes. With this process, they were able to achieve electrode capacities of $>100 \mathrm{mAh} / \mathrm{g}$ at $200 \mathrm{C}$ and $60 \mathrm{mAh} / \mathrm{g}$ at $400 \mathrm{C}$, although using an electrode with a very dilute concentration of active material. ${ }^{99}$ In view of these remarkable results, they concluded that electrode materials with extremely high-rate capability will "blur the distinction between supercapacitors and batteries, "99 a point that we will return to later in this article. More recent work has shown that the high rates achieved in LFP are associated with the ability of the material to operate via a metastable $\mathrm{Li}_{x} \mathrm{FePO}_{4}$ solution during high-rate cycling; the classical model of intercalation in material that operates via a two-phase reaction, involving nucleation, growth, and movement of a phase boundary is no longer appropriate, at least at high rates. ${ }^{105-108}$

\section{Electrode morphology and structuring}

Micro- and nanostructuring of electrode particles can be used to achieve higher capacity and rate capability in LIBs. ${ }^{109,110}$ In particular, it can (i) increase the electrode/electrolyte interface area thereby enabling increased charge storage; (ii) provide shorter path lengths for both electron and $\mathrm{Li}$ ion diffusion that can improve high-rate performance; and (iii) more readily accommodate the strain associated with $\mathrm{Li}$ insertion/removal, which can enable increased cycle life. However, set against these advantages are some disadvantages, which include (i) increased undesirable electrode/electrolyte reactions due to higher surface area leading to higher impedance, reduced rate, and diminished cycle life; (ii) less-dense packing of active material (i.e., lower "tap density"), leading to lower volumetric energy densities; and (iii) potentially more complex and/or costly electrode synthesis, which preclude use in large-scale battery manufacturing. ${ }^{109}$ When optimizing electrode materials specifically for high-rate performance, the contribution of micro- and nanostructuring to the kinetics of charge storage can be complicated by how the porosity is introduced in the electrode. For electrode materials in which electronic conductivity and charge transfer reactions are not rate limiting, ion transport in the host materials and/or the percolating electrolyte of $3 \mathrm{D}$ porous materials can become limiting. ${ }^{111}$

Numerous approaches have been proposed to structure electrode materials at the microscale to increase electrolyte access. These include laser structuring, ${ }^{112,113}$ hard templating (e.g., colloidal crystal), ${ }^{114-116}$ and soft templating ${ }^{114,117}$; however, it is necessary to establish the C-rates over which the structuring or templating process effectively increases capacity or capacity retention with high rates. ${ }^{112}$ If the Li ion concentration becomes depleted at surfaces due to fast cycling, this can result in large concentration overpotentials, which limit the rate of the charge transfer reactions. ${ }^{112}$ At high charging/discharging rates, highly tortuous Li ion diffusion paths can restrict access to some regions of the current collecting surface, which can significantly curtail the capacity. ${ }^{118}$ One approach by which high capacity can be retained with high-rate cycling is to use a dual-scale porosity, which combines channels, coated with a porous matrix, aligned to be perpendicular to the current collector. ${ }^{111}$ This arrangement can facilitate $\mathrm{Li}$ ion access to a $3 \mathrm{D}$ volume without depletion of ions at the electrode surface. It can also allow for thicker electrodes to be used for increased capacity. ${ }^{118}$ It is important that both electrodes in a device can support high charging and discharging rates. For example, although laser structuring of a graphite anode can increase capacity over the range of $1-3 \mathrm{C}$, at faster rates, the device performance can become limited by the cathode. ${ }^{112}$

Nanoscale structuring, through formation of nanoparticles, nanotubes, nanofibers, and nanowires, can also be used to increase Li ion flux at surfaces. ${ }^{109,119-127}$ Additional benefits can arise from (i) space charge effects at the electrode/electrolyte interfaces and (ii) spatial confinement, both factors having the potential to change the thermodynamics of charge transfer reactions from that observed in bulk materials. ${ }^{109,125,128,129}$ Nanoconfinement (see Fig. 4) can impact ion transport in the electrolyte, phase transitions, and solvation structures. ${ }^{125,130-132}$ It has been shown to enhance charge storage in electrochemical capacitors, which have emerged as high-rate complementary energy storage solutions to batteries. ${ }^{133-135}$

Hierarchical micro-nanostructured electrodes can exploit the positive attributes of nanostructures for increased surface area, nanometer diffusion lengths, nano-confinement effects, and microstructures for improved stability and ease of handling during electrode preparation. ${ }^{119,136}$ They can be fabricated through the aggregation of nanosized crystallites to form larger, porous agglomerates, which can be then further grouped into micrometer-sized grains (e.g., see Fig. 5). ${ }^{79}$ The resulting multiscale porosity can enable effective penetration of the electrolyte, with the distance for $\mathrm{Li}$ ion diffusion lengths being minimized within the electrochemically active nanoparticles. The application of this hierarchical structuring process using LTO nanoparticles enabled the achievement of a capacity of $170 \mathrm{mAh} / \mathrm{g}$ at 50C with minimal capacity fading after 1000 cycles. ${ }^{79}$ The higher capacities observed in the hierarchically structured electrode in comparison with bulk LTO were partially attributed to the formation of a Ti-rich surface layer. ${ }^{79,137}$ This highlights that nanostructuring may also introduce benefits in terms of metal-oxide surface stoichiometry ${ }^{138}$ in addition to improved electrolyte access and greater accommodation of strain. Understanding the surface atomic structure is also critical to the understanding of electrolyte decomposition side reactions that result in gas generation and SEI formation. ${ }^{138}$

Another common approach to fabricating hierarchical micro-nanostructures is to coat $3 \mathrm{D}$ microstructured current collectors (e.g., metal foams), which provide a percolating network for both electron and ion pathways with an electroactive nanomaterial. ${ }^{136}$ Coating can be achieved by thermal oxidation, ${ }^{139,140}$ 
a)

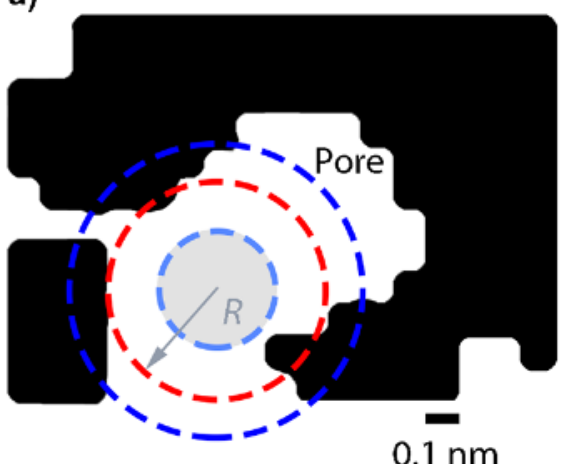

b)

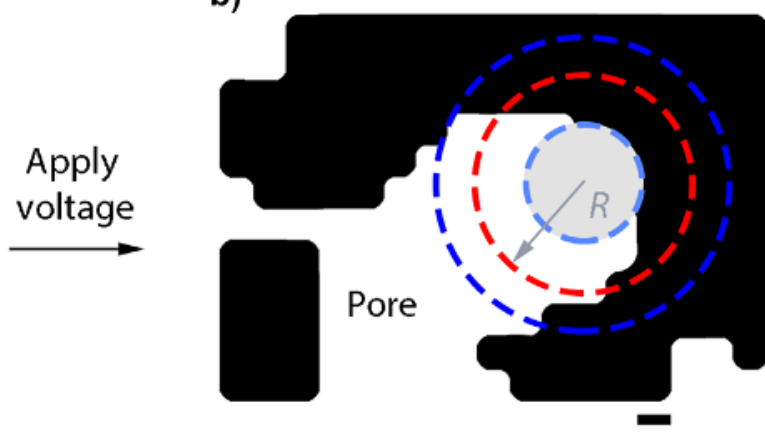

$0.1 \mathrm{~nm}$
$R$-bare ion

$R$-hydrated ion

R-cut off

Figure 4. Nanoconfinement of a hydrated ion in a 3D carbon nanopore. Schematics showing (a) a low level (i.e., retention of some hydration) and (b) a higher level of nanoconfinement. The light blue, red and dark blue circles represent the bare ion, the hydrated ion, and the cutoff radius for which the degree of confinement is determined, respectively. In this model, the ions are assumed to be hard spheres that can approach the electrode surface as close as their bare ion radius (reproduced with permission from Prehal et al. ${ }^{135}$ ).
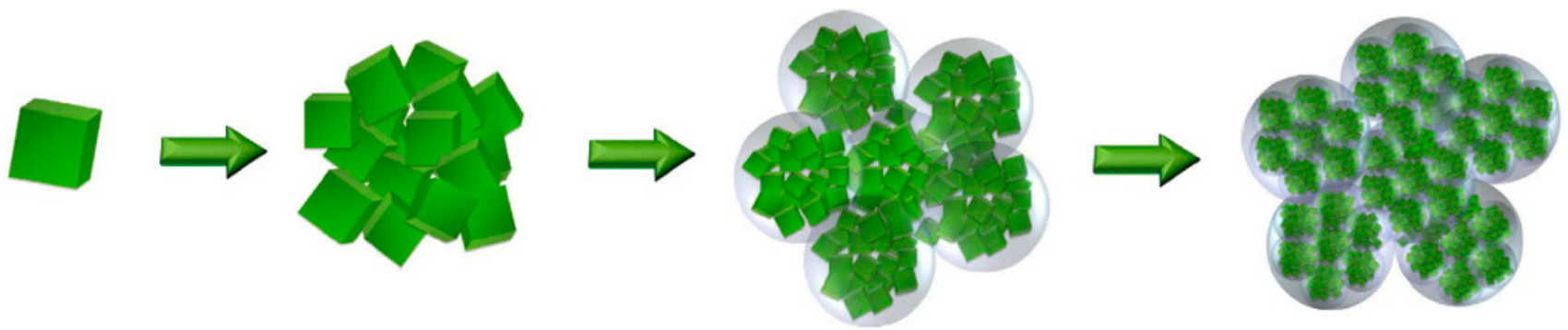

Figure 5. Hierarchical micro-nanostructure through aggregation. Schematic depicting the hierarchical aggregation of crystalline nanoparticles into the progressively larger microparticles used for electrode fabrication (adapted from Odziomek et al. ${ }^{79}$ and reproduced under Creative Commons Attribution 4.0 International License).

electrodeposition, ${ }^{141}$ casting of a slurry, ${ }^{136,142,143}$ or surface anodization. ${ }^{144,145}$ With processes where the active material is directly grown on the metal scaffold, the need for binder can be eliminated. Typical fluoropolymer binders are insulating and electrochemically inactive; they decrease gravimetric energy density and increase the resistive losses and hence power losses, especially under high-rate operating conditions. Binder material can also swell in commonly used organic electrolytes, leading to poor stability and irreversible capacity losses. ${ }^{146,147}$ Anodization of metal foams in fluoride-containing electrolytes to form nanotube arrays on the foam surface is one approach that has been successfully used to fabricate hierarchically structured electrodes. ${ }^{144,145}$ Figure 6 depicts the growth of $\mathrm{TiO}_{2-x}$ nanotubes directly on a Ti foam current collector. The foam allows increased $\mathrm{Li}$ ion access to the surface structures and the 20-50 nm thickness of the $\mathrm{TiO}_{2-x}$ nanotube walls improves electronic conductivity of the electrode. ${ }^{145}$

A key practical concern for all structuring methods is whether a process can be practically scaled to manufacturing and whether the improvements in rate or cycle life that can be achieved result in a commercial advantage. Nanostructuring generally reduces tap density and so it is necessary to consider volumetric as well as gravimetric energy and power densities. ${ }^{95,148}$ Also, although the larger surface area introduced by nano/micro-structuring can be beneficial for high-rate performance, it can increase the probability of undesirable side reactions and consequently reduce cycle life. To minimize this possibility, as is the case for supercapacitors, highly pure materials will be required and this can increase battery cost.

\section{Electrolyte selection}

The rate and cycle life of LIBs depend strongly on the electrolyte used. ${ }^{149}$ Most currently produced LIBs utilize electrolytes comprising $\mathrm{Li}$ ion salts (e.g., 1.0 $\mathrm{M} \mathrm{LiPF}_{6}$ ) in a mixture of organic solvents. Common solvents used include ethylene carbonate (EC), dimethyl carbonate (DMC), diethyl carbonate, propylene carbonate (PC), and ethyl methyl carbonate. ${ }^{62,150}$ Organic solvents permit a voltage operating window that is approximately three times larger than that possible with equivalent salt concentrations in aqueous electrolytes due to their greater oxidative and reductive stability compared with water. This wider voltage window results in LIBs having enhanced gravimetric 
a)

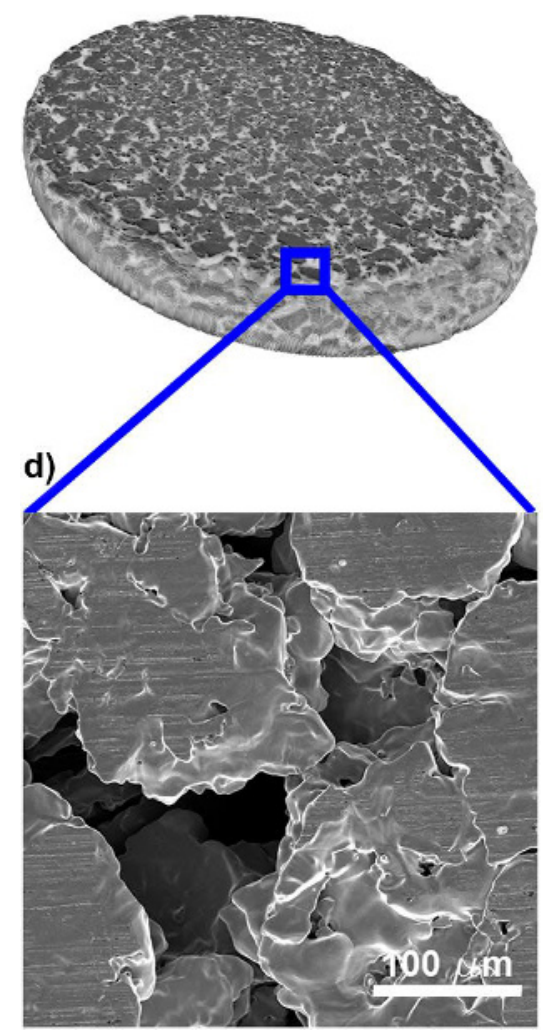

b)

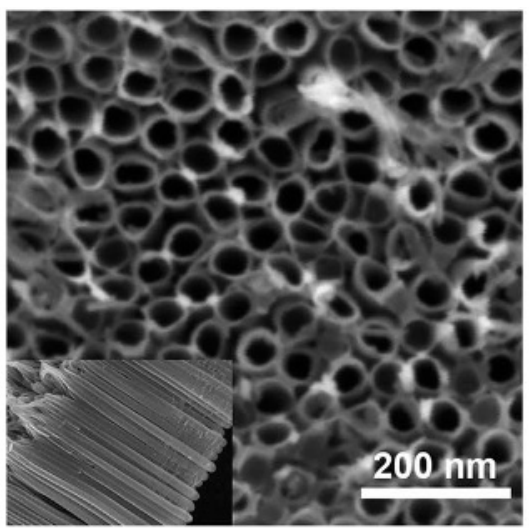

e)

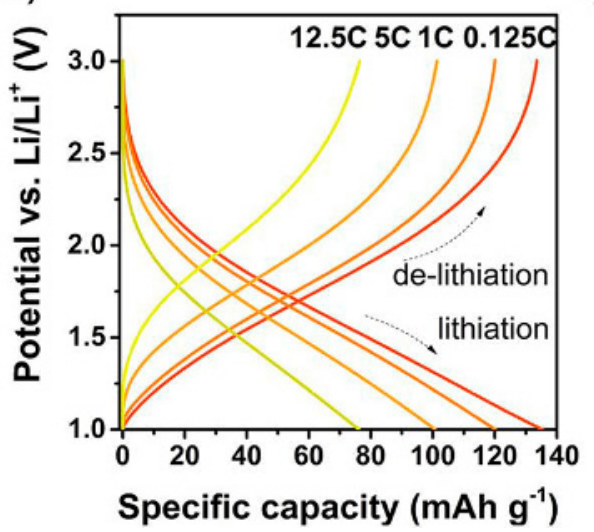

c)

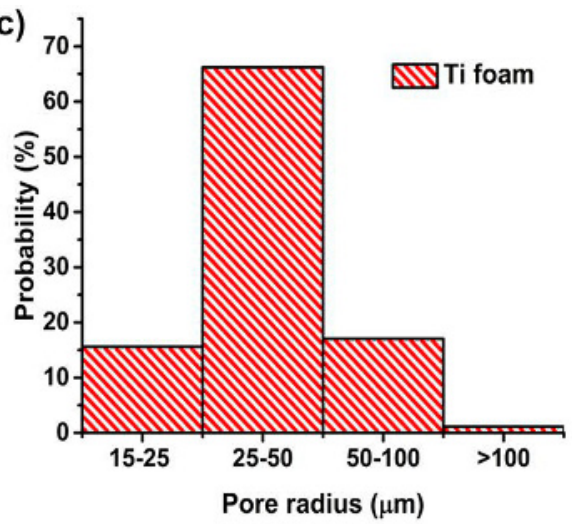

f)

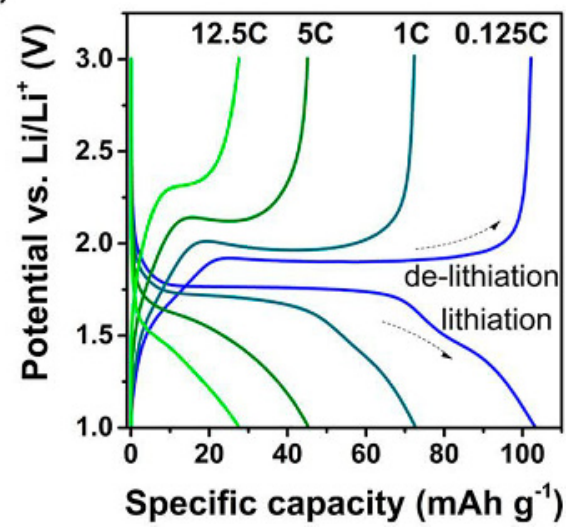

Figure 6. Hierarchically structured $\mathrm{TiO}_{2-x}$ anode formed by anodization of a Ti foam current collector. (a) and (d) Low- and high-magnification images of the $\mathrm{Ti}$ foam, (b) scanning electron microscope image of amorphous $\mathrm{TiO}_{2-x}$ nanotubes formed on the foam surface, and (c) distribution of pore sizes as determined by X-ray computed tomography. Galvanostatic charge/discharge curves are shown in (e) and (f) for amorphous and crystalline $\mathrm{TiO}_{2-x}$ nanotube arrays on Ti foams, respectively (adapted from Jiang et al. ${ }^{145}$ ).

and volumetric energy densities compared with batteries that use aqueous electrolytes. However, the ionic conductivities of the organic electrolytes are lower (e.g., $1-12 \mathrm{mS} / \mathrm{cm}$ for $1.0 \mathrm{M}$ $\mathrm{LiPF}_{6}$ in $\mathrm{EC} / \mathrm{DMC}^{62,151}$ ) than those of aqueous electrolytes [(e.g., $600-825 \mathrm{mS} / \mathrm{cm}$ for $\sim 1.2 \mathrm{~g} / \mathrm{cm}^{3} \mathrm{H}_{2} \mathrm{SO}_{4}$ (aq.) used in lead acid batteries ${ }^{152}$ ]. To help compensate for the low conductivity of the electrolyte, high-rate Li-ion cells typically use thin electrode stacks (e.g., $\leq 100 \mu \mathrm{m}$ thick). ${ }^{118}$

One rate-limiting property of the organic electrolytes is their low $\mathrm{Li}^{+}$transference number, $t_{+}$, of $<0.5 .{ }^{153,154}$ This means that the ionic current is carried predominantly by the counter ion and not the $\mathrm{Li}^{+}$on charging and discharging. The low transference number arises from the preferential solvation of $\mathrm{Li}^{+}$compared with its counter ion in carbonate solvents and results in a concentration gradient that limits the rate at which the battery may be charged or discharged. It also limits the charging voltage, and hence energy density of the battery, through an increased concentration overpotential and this, in turn, places an upper limit to the thickness of the electrodes used. Doyle et al. showed (by simulation) the importance of using an electrolyte with a high $t_{+}$for high-power batteries and demonstrated significant enhancement in terms of rate capability when using a $t_{+}=1.0 \mathrm{Li}$ ion polymer electrolyte over an electrolyte with $t_{+} \approx 0.2$ even with an order-of-magnitude decrease in electrolyte conductivity in the former. ${ }^{153}$ Improvements in energy density were especially evident at high charging/discharging rates when Li ions became depleted with low $t_{+}$electrolyte due to their slower transport to the electrode surface.

One approach to increasing the $\mathrm{Li}$ ion transference number in organic electrolytes is to use larger and hence lower mobility polymeric anions. ${ }^{155}$ Design of such electrolytes requires maximizing both the free Li ion concentration and localized charge density of the anion groups on the polymer backbone, while keeping the polymer content as low as possible so as to not overly increase the electrolyte viscosity. ${ }^{155}$ However, to-date, very few attempts at improving ion conductivity have been realized through this approach because the choice of anions suitable for Li ion electrolytes is limited ${ }^{62}$ and anion suitability also depends on their electrochemical stability at electrode surfaces. Instead, solvent composition tailoring has been the main tool for manipulating electrolyte ion conductivity due to the availability of a vast number of candidate solvents. For solvated $\mathrm{Li}$ 
ions to migrate quickly under an electric field, ideally the solvent molecules prevent the Li cations and the electrolyte anions from forming close ion pairs. Solvents with a higher dielectric constant screen ion interactions; however, these solvents typically have a higher viscosity, which acts to slow ion movement in an electric field. Consequently, solvent mixtures are used, with one component selected for ion shielding (i.e., high dielectric constant) and the other(s) selected for their low viscosity. ${ }^{62}$

As mentioned in the earlier discussion of LIB Technology, an SEI typically forms at LIB anode surfaces due to reduction reactions involving the chemical species in the electrolyte. Migration of ions through this surface layer is typically the rate-limiting step for most LIB chemistries. ${ }^{46,47,62}$ An analogous layer called the cathode-electrolyte interface (CEI) forms on cathodes by oxidation reactions involving electrolyte components at high potentials but the impact of this thin or possibly transient layer on battery cell performance is generally considered to be less significant. ${ }^{50,97}$ The nature of the formed SEI depends on many factors, including the anode material and electrolyte composition. When the SEI continues to grow on cycling, it increases the cell impedance and eventually consumes the finite quantity of $\mathrm{Li}$, limiting the cycling life of the battery. Consequently, some control over SEI formation and growth is critical for the achievement of LIBs with high rate capability and cycle life. One option is to use electrode materials with a higher (i.e., less negative) reduction potential (e.g., those based on early transition metals, as discussed previously for electrode materials), so that the parasitic reactions and hence SEI formation can be minimized; however, the increased rate and cyclability are achieved at the cost of capacity due to the significantly reduced lower cell voltage. Furthermore, the less-passivated surfaces of the high potential anodes can give rise to challenges, such as gas generation and pressure buildup in the cell. ${ }^{156-158}$

Another option is to engineer an artificial SEI to achieve high and stable conduction of Li ions to the electrode surface. ${ }^{48}$ The SEI composition can be tuned by using additives in the electrolyte that will react at the surface before the electrolyte solvent and anion species. ${ }^{47}$ Another option is to carefully select the choice of solvent as some solvent species have been shown to form more stable insulating layers without seriously impacting the Li ion conduction. Takenaka et al. confirmed, using atomistic simulations (see Fig. 7), that an EC-based SEI film can prevent excess reduction of electrolyte on a graphite anode surface while still allowing $\mathrm{Li}$ ions to pass through. In contrast, a PC-based film could not sufficiently insulate the anode surface, allowing continued electrolyte reaction despite PC only differing from EC molecules by the presence of their methyl side groups. ${ }^{159}$ This example highlights the need for a greater understanding of SEI formation and, in particular, use of simulations to guide the development of electrolytes for stable SEI layers with high conductivity for high-rate LIBs. ${ }^{47,48,159}$

Another electrolyte strategy that may offer a path toward longer cycle life and perhaps also higher rate is to use superconcentrated, or high ion-to-solvent ratio, electrolytes. ${ }^{160-162}$ Although lowering ionic conductivity, ${ }^{160}$ this newer class of electrolyte has been proposed to provide greater oxidative
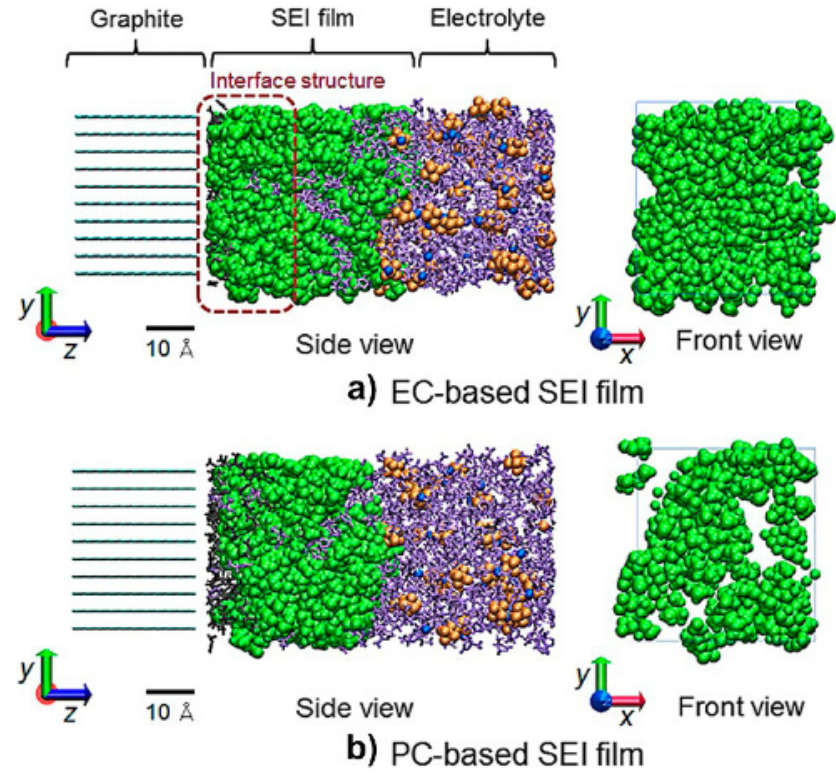

Figure 7. Atomistic models of SEl films formed over a graphite anode. Models showing (a) an EC-based electrolyte, and (b) a PC-based electrolyte (green = SEl film; blue $=\mathrm{Li}^{+}$; gray $=\mathrm{PF}_{3}, \mathrm{C}_{2} \mathrm{H}_{4}$, or $\mathrm{C}_{3} \mathrm{H}_{6}$; purple = $\mathrm{EC}$ or $\mathrm{PC}$; orange $\left.=\mathrm{PF}_{6}\right)\left(\right.$ reproduced with permission from Takenaka et al. ${ }^{159}$ ).

stability (allowing higher cycling voltages and commensurately larger energy densities), reduced volatility and flammability, and enhanced Li ion interfacial transport. ${ }^{161} \mathrm{~A}$ key reason for the continued use of the 1.0 $\mathrm{M} \mathrm{LiPF}_{6}$ electrolyte in commercially produced LIBs has been the ability for this salt to protect against the corrosion of the $\mathrm{Al}$ current collectors by forming an $\mathrm{AlF}_{3}$ coating on the cathode through the reaction of hydrogen fluoride ( $\mathrm{HF}$, a breakdown product of $\left.\mathrm{PF}_{6}{ }^{-}\right)^{163}$ with Al. ${ }^{61,164}$ However, HF also acts to dissolve the metal oxide cathode material, ${ }^{165}$ releasing metal ions, which can subsequently deposit on the anode where they further catalyze the reduction of electrolyte solvent. 166,167 This degradation process consumes Li ions and thickens the SEI for graphite anodes and, in doing so, decreases both the rate capability and cycle life of the battery.

Wang et al. have demonstrated the use of the more stable $\mathrm{LiN}\left(\mathrm{SO}_{2} \mathrm{~F}\right)_{2}$ (LiFSA) salt mixed with DMC at very high salt: solvent molar ratios of 1:1.1 (compared with $1: 10.6$ for the $1.0 \mathrm{M}$ $\mathrm{LiPF}_{6}$ in $\mathrm{EC} / \mathrm{DMC}$ ) to achieve cathode stabilities at potentials of up to $5 \mathrm{~V}$ versus $\mathrm{Li}^{+} / \mathrm{Li}$, promising long cycle life and high rate capability with enhanced safety. This superconcentrated electrolyte forms a 3D network of anions and solvent molecules that coordinates the $\mathrm{Li}$ ions and effectively inhibits the dissolution of both the $\mathrm{Al}$ cathode current collector as well as the transition metal oxides at potentials of up to $5 \mathrm{~V} \cdot{ }^{160}$ In electrolytes with salt-to-solvent molar ratios of $>1: 2$, the solvent molecules are mostly coordinated by $\mathrm{Li}$ ions in the primary solvation shell, and this decreases the reactivity of the solvents molecules at the electrolyte surfaces. ${ }^{162}$ Although some sacrifice in electrolyte conductivity results with high salt-to-solvent electrolytes $\left(\sim 1.1 \mathrm{mS} / \mathrm{cm} \text { for LiFSA at } 30{ }^{\circ} \mathrm{C} \text { with } 1: 1.1 \text { molar ratio }\right)^{160}$ 
compared with $\sim 6 \mathrm{mS} / \mathrm{cm}\left(1: 10.6\right.$ molar ratio) for $1.0 \mathrm{M} \mathrm{LiPF}_{6}$ in $\mathrm{EC} / \mathrm{DMC},{ }^{151}$ the improvement in cycle life that may result from the diminished reactivity at electrode surfaces may be valuable for services, such as grid stabilization, depending on the cost of the salt.

\section{Strategies considered together}

Typically, any high-rate LIB device design will draw upon more than one of the aforementioned design strategies; however, there are also interdependencies. For example, changes in electrolyte to optimize SEI formation need to take into account the materials used for the electrode. If an anode comprising an early transition metal is adopted, specifically for increased cycle life, then additives or specific solvent combinations to enhance the formation of an ion conductive SEI may not be required as the higher voltage minimizes reactions involving electrolyte species. Similarly, if electrode structuring is used, consideration should be directed at how a structured electrode volume with different diffusion length scales impacts the electronic and ionic conductivity of the electrode and even SEI formation. Identifying the rate-limiting steps and processes on charging and discharging both the anode and cathode becomes the key to optimizing battery cells for improved rate and cycle life.

This independency of strategies highlights the importance of improving our understanding of all mechanistic aspects of LIBs if we are to effectively engineer storage devices capable of high rates and very long cycle lives at costs that are competitive for grid stabilization services. The above discussion of SEI formation highlights the importance of simulation and modeling in this next phase of LIB design and evolution. The electrochemical reactions involved in these cells are complex, and greater understanding of the rate-limiting steps in fast charge transfer reactions is required. For many years, it has been assumed that $\mathrm{Li}$ ion diffusion limits charging/discharging rates ${ }^{168}$; however, recent reports are now suggesting that the charge transfer kinetics may also become limiting in cases where Li ion diffusion may be rapid. ${ }^{145,169}$ This suggests that more advanced simulation models may be required to predict ionic and electronic flow though percolating porous networks and rates of charge transfer reactions. ${ }^{169,170}$

\section{Integration into systems}

A possibly advantageous attribute of high-rate LIB electrodes is that the linearly responsive capacitive-shaped (potential versus charge) discharge curves typically observed with fast electrode reactions can enable energy storage control systems to more reliably determine the state-of-charge (SoC) of the battery. Figure 8(a) shows discharge curves for a TNO/NCM LIB $(1 \mathrm{C}$ capacity $=49 \mathrm{Ah})$ at different C-rates. Unlike typical flat battery discharge profiles, for the range of rates shown, it is possible to determine the SoC of the battery due to the constantly declining voltage with discharge. Knowledge of the SoC during charging and discharging can reduce the complexity of integrating energy storage functionality in power electronics and facilitate more flexible grid stabilization systems that maintain

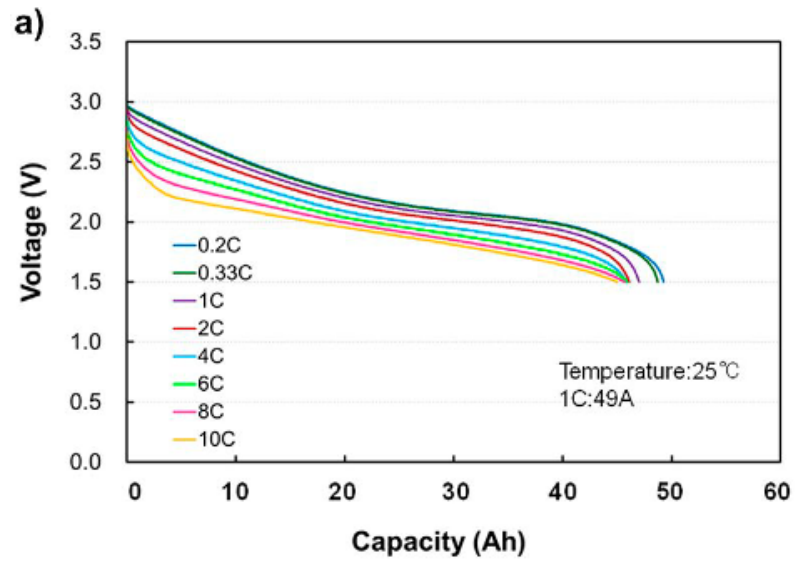

b)
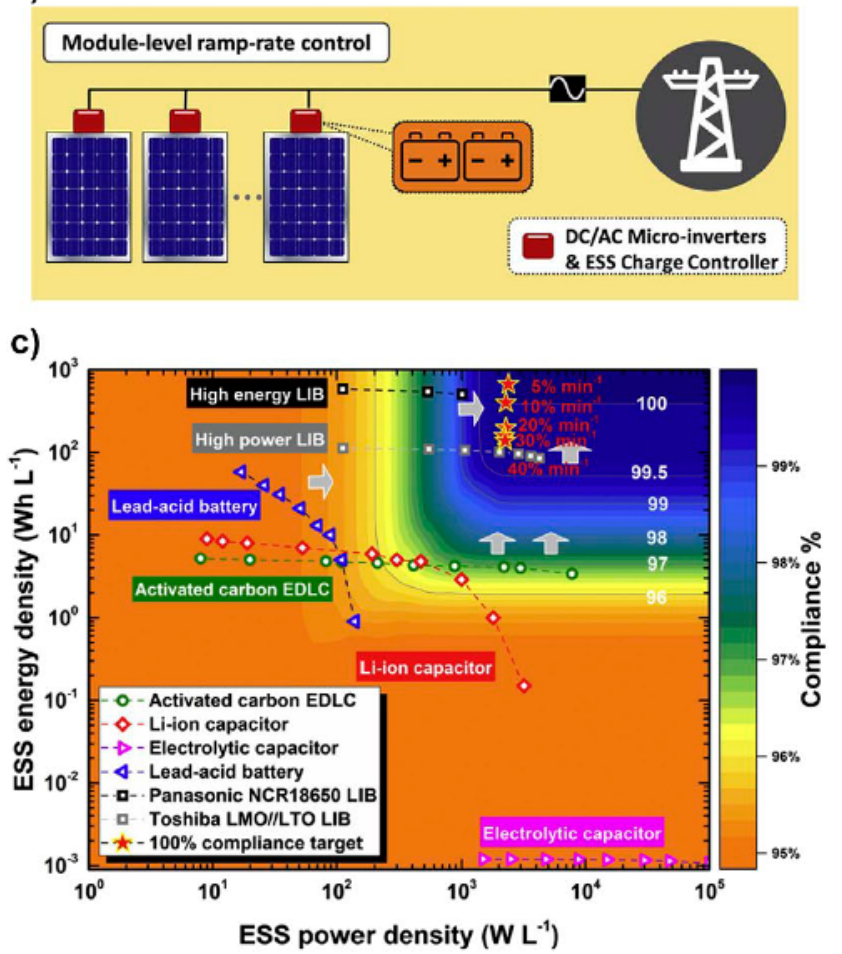

Figure 8. Capacitive-shaped discharge curves of high-rate LIBs allowing the SOC to be beneficially used when integrating energy storage with power electronics. (a) Capacitive-shaped discharge curves for a high density TNO/NCM LIB at different C-rates at $25^{\circ} \mathrm{C}$ (reproduced with permission from Takami et al. ${ }^{93}$ ), (b) configuration of a PV system with an energy storage system (ESS) integrated in the PV module junction box for ramp rate control, and (c) compliance (\%) for a range of different ESS technologies to achieve a power ramp rate of $10 \%$ per min power assuming that the ESS in (b) has a maximum volume of $0.1 \mathrm{~L}$ (adapted with permission from Jiang et al. ${ }^{22}$ ).

the LIB in an optimal SoC by rapid-response charging from the grid when demand for electricity is low. We note, however, that too large variations in voltage require additional circuitry to manage. Integration of energy storage SoC into optimization algorithms for ramp rate control ${ }^{31,32}$ and frequency stabilization $^{29,33}$ may provide a way to increase the battery lifetime by 
decreasing the frequency and duration of deep discharges or charges, which tend to degrade LIBs. ${ }^{50}$ If the cost of LIBs can be decreased significantly (see later discussion), then it may become possible to integrate compact storage elements within smart junction boxes of PV modules (e.g., in DC-DC power optimizers or microinverters) to limit the ramp rate of generated power in the presence of intermittent insolation [see Figs. $8(\mathrm{~b})$ and $8(\mathrm{c}){ }^{2}{ }^{22}$ This can contribute to the smoothing of high-frequency power changes when exporting power to the grid.

The linearly responsive capacitive-shaped discharge curves and the higher discharge rates that can be achieved with highrate LIBs present an opportunity for high-rate LIBs to replace higher cost electrochemical capacitors in industrial applications. ${ }^{95,99}$ Kang and Ceder reported the ability for LIB electrode materials to support volumetric power densities of $\sim 65 \mathrm{~kW} / \mathrm{L}$ ( $\sim 25 \mathrm{~kW} / \mathrm{L}$ at a battery level),${ }^{99}$ which exceeds that of a Maxwell BCAP3000 P270 supercapacitor ( 7.5 kW/L, Maxwell Technologies, San Diego, California). ${ }^{171}$ Provided that such high-rate LIB materials can also approach the long cycle lives of supercapacitors, they may find applications in regenerative breaking, emergency power supplies, and heavy transport. ${ }^{172}$ Their increased energy density compared with carbon-based supercapacitors may also enable new solar-powered applications, which use embedded localized power sources. Examples include solar-powered tools and devices for remote areas and compact integrated solarpowered devices for space operation (e.g., energy buffers for solar-powered antennae for CubeSats). ${ }^{173}$

\section{Cost considerations}

Schmidt et al. recently reported product energy and power price manufacturing experience curves for four categories of $\mathrm{Li}$ ion technology: (i) electronic $(\mathrm{C} \sim 1$ ); (ii) $\mathrm{EV}(\mathrm{C}>1)$; (iii) residential $(\mathrm{C} \sim 1)$; and (iv) utility $(\mathrm{C} \sim 1) .{ }^{174}$ Of these categories, the product power price of EV LIB packs were lowest $\left[<\mathrm{US}_{2015} \$ 100 / \mathrm{kW}\right.$ (capacity)], with an experience rate of $16 \%$. From the indicative $\mathrm{C}$ rates for each category, it is assumed that the residential and utility categories are focused more on "energy" or capacity applications (e.g., load shifting) and that the higher power EV category is perhaps the best indicator of manufacturing experience for high-rate LIBs that could be used for grid stabilization applications. EV LIBs are expected to approach material costs (currently estimated at $<\mathrm{US} \$ 100 / \mathrm{kWh}$ ) and so it is reasonable to expect that product costs of electrochemical storage for electrical grid stabilization could approach similar values. ${ }^{174}$

However, what is critical for grid stabilization is the "service cost" of providing power stabilization. If alternative options for frequency stabilization are costly, then higher energy storage system costs may be tolerated for this application than for EVs and longer term storage. ${ }^{36}$ Service costing is further complicated by the fact that the expected cycle life of LIBs performing high-rate charging/discharging for grid stabilization may differ from that when the same battery technology is used for other applications. For example, as mentioned above, if control systems implement strategies, which maintain the SoC at an optimal state, then deep cycling may be minimized, thereby prolonging the battery life over use cases where batteries are fully discharged/recharged.

In Lazard's 2016 analysis of cost of storage, ${ }^{175}$ LIBs were assessed to be the most cost-effective technology for frequency regulation (lower end electricity cost of US\$159/MWh) and one of the cheaper options for peaker replacement (lower end electricity cost of US $\$ 285 / \mathrm{MWh})$. In 2017, Lazard revised their reporting structure to consider (i) in front of the meter use cases (microgrid, peaker replacement, and distribution) and (ii) behind the meter use cases (residential and commercial). ${ }^{176}$ They viewed frequency regulation as a service that could be provided by each of peaker replacement, microgrid, and commercial (behind the meter) use cases and concluded that LIBs are the only energy storage technology that can span this operational range with a cost-competitive service. Further reduction in costs from manufacturing experience and increased cycle life is expected to increase this advantage even further.

\section{Resource availability}

An often-cited concern for large-scale adoption of LIBs for portable electronics, EVs, and renewable energy integration is the availability of Li. Lithium is the 25 th most abundant element in the earth's crust and it is found all over the world, including in the oceans. ${ }^{177}$ However, extraction of Li requires both favorable environmental surroundings and scientific expertise. Most Li production, typically in the form of $\mathrm{Li}_{2} \mathrm{CO}_{3}$ or LiOH, ${ }^{178}$ comes from Australia, Chile, Argentina, and China. It is extracted from continental brines in salt lakes, pegmatite minerals, such as spodumene $\left(\mathrm{LiAlSi}_{2} \mathrm{O}_{6}\right)$ and petalite $\left(\mathrm{LiAlSi}_{4} \mathrm{O}_{10}\right)$, or clays. ${ }^{177,179,180} \mathrm{Global}$ economically extractable reserves are heavily concentrated in these four countries, but additional resources exist in Bolivia, United States, Canada, Congo, Russia, and Serbia, with smaller reserves and production in Portugal, Brazil, and Zimbabwe. ${ }^{179,180}$ Driven by the growth in manufacturing of LIBs, global Li production has increased by about $20 \%$ per annum since $2000,{ }^{178}$ and in 2017 , the LIB market accounted for about $50 \%$ of the 43,000 metric tons of $\mathrm{Li}$ consumed. ${ }^{180}$ The economically recoverable global Li reserves are estimated to be 16 million tons, with total resources of 53 million tons being estimated by the 2018 U.S. Geological Survey analysis. ${ }^{180}$ Figures for available reserves are constantly changing and the fraction of total resources that are economically extractable depends on the maturity of extraction technology 177,181-183 and value of the commodity, the latter having more than tripled in the last five years for $\mathrm{Li}^{184}$

Recent analysis suggests that total demand for Li could increase to 80,000 tons per annum by $2030,{ }^{179}$ and consequently, a number of new Li mining projects are already underway. ${ }^{178}$ Lithium is also extensively used in glasses and ceramics (applications that are also predicted to increase in the future); however, availability of Li is not expected to significantly impact LIB production in the next 20 years. Narins suggests that the world could triple its 2016 production and still have enough $\mathrm{Li}$ for 135 years solely from currently known reserves and not 
considering new sources of $\mathrm{Li}$ that are being investigated. ${ }^{185}$ Despite these abundant reserves, $\mathrm{Li}_{2} \mathrm{CO}_{3}$ prices rose from approximately US $\$ 5,000$ per metric ton in $2010^{178}$ to US $\$ 15,000$ 24,000 per ton early in $2018 .{ }^{180}$ This increase was due to a supply-demand imbalance, ${ }^{178}$ and the correction of this imbalance is already being observed as prices are falling. Morgan Stanley are predicting a $45 \%$ cost reduction by 2021 due to production exceeding demand, ${ }^{186}$ though there is some concern that the required ramp-up in production may not be fast enough to meet demand. ${ }^{187,188}$

Greater concern should arguably be directed at other metals that are required by LIBs and, in particular, Cu and Co. Due to its thermal and electrical conductivity and its resistance to corrosion, $\mathrm{Cu}$ is a major industrial metal, ranking third after Fe and $\mathrm{Al}$, in terms of quantities consumed. The electronics industry is the largest consumer of $\mathrm{Cu}$ and accounted for $39 \%$ of global demand in 2015. ${ }^{189}$ Copper is required for electrical connectors and cables, a demand that is expected to increase with growing adoption of LIBs to support transport electrification and renewable energy integration. Each EV requires four times as much $\mathrm{Cu}$ as its gasoline counterpart, and this comparison does not include the $\mathrm{Cu}$ used for recharging infrastructure and electricity generation. ${ }^{185}$ In addition, renewable energy generation is estimated to require 11-40 times as much $\mathrm{Cu}$ as conventional fossil fuel-based power generation. ${ }^{190,191}$ In an assessment of the resources required to support future large-scale implementation of solar PV, wind, and concentrated solar thermal power, Hertwich et al. concluded that $\mathrm{Cu}$ was the only material for which supply may be a concern. ${ }^{190}$ Copper is currently one of the most recycled metals ${ }^{192}$; however, the projected future demand suggests that improved recycling processes may be required as the average recycled content remains below $50 \%{ }^{192,193}$

In 2017, 48,000 metric tons of Co was consumed by the battery industry (from a total world production of 110,000-117,000 metric tons ${ }^{194,195}$ ) and this usage is expected to increase to 127,000 metric tons by 2025 based on estimates of LIB production for transport electrification. ${ }^{195,196} \mathrm{As}$ for $\mathrm{Li}$, Co is not extraordinary rare, but it is difficult to extract in purities high enough to justify production, and so currently, most Co is extracted as a by-product of $\mathrm{Cu}$ and Ni mining. Additionally, unlike the reasonable geographical diversity of Li resources, the Democratic Republic of Congo (DRC) extracted more than $50 \%$ of the world's Co in 2017. ${ }^{188,196,197}$ Added to concerns about the political stability of the DRC, China is dominant in Co refining $^{188,198}$ and relies on the DRC for over $90 \%$ of its Co supply. ${ }^{197}$ These supply chain factors make for a risky situation for LIB producers, and this situation may be reflected in the Co price rapidly increasing from $\sim$ US $\$ 30,000$ per metric ton in 2014 to over US $\$ 80,000$ in $2017 .{ }^{196}$ From the long-term perspective of global economic reserves or total resources, there is only about half as much $\mathrm{Co}$ as $\mathrm{Li}$ and a $\mathrm{LiCoO}_{2} \mathrm{LIB}$ requires several times more Co than Li by mass. In consideration of these factors, a global shift is occurring in the research and commercial battery communities toward less Co-intensive cathode materials, such as $\mathrm{NCA}\left(\mathrm{LiNi}_{0.8} \mathrm{Co}_{0.15} \mathrm{Al}_{0.05} \mathrm{O}_{2}\right)$ and Ni-rich NMC $\left(\mathrm{LiNi}_{0.8} \mathrm{Mn}_{0.1} \mathrm{Co}_{0.1} \mathrm{O}_{2}\right)$, however there are already concerns about the long-term sustainability of Ni. One advantage that high-rate LIBs may leverage is that they can make use of the less resource-constrained $\mathrm{LiFePO}_{4}$ cathode materials, as energy density may not be such a premium for grid stabilization functionality. Additionally, by using higher voltage anode materials, $\mathrm{Al}$ can substitute for $\mathrm{Cu}$ as the anode current collecting metal, which decreases the total electrode cost and mass and eases the demand on $\mathrm{Cu}$ resources.

\section{Recycling}

Lead-acid batteries are extensively recycled due to the toxicity of $\mathrm{Pb}$, the relatively simple recycling process, and government regulations. In the United States, they are managed as Universal Waste and must be recycled. ${ }^{199}$ However, similar recycling regulations do not exist for LIBs, and currently, most LIBs are landfilled as recycling has not been proven to be economically viable at scale. ${ }^{184}$ Recycling of LIBs is complex because of the mix of materials used in the batteries. If spent LIBs are burned as a general type of solid waste, they will produce hazardous gases, such as HF due to the fluorinated electrolyte. ${ }^{200}$ In addition, $\mathrm{Li}$ is extremely reactive with water, making fire a risk for both landfilling and also recycling. Recycling of LIBs typically involves pyrometallurgical (smelting) and/or hydrometallurgical (chemical separation) processes. ${ }^{184,201,202}$ Pyrometallurgical methods are usually limited to recovering $\mathrm{Co}, \mathrm{Ni}$, and $\mathrm{Cu}$; however $\mathrm{Al}, \mathrm{Mn}$, and $\mathrm{Li}$ are lost in the slag. ${ }^{184}$ Additionally, these processes require a large amount of energy with 5000 MJ of heat being required per metric ton of battery treatment (for smelter and gas cleanup). ${ }^{184}$ Hydrometallurgical processes can comprise many different chemical treatments (e.g., precipitation, solvent extraction, ion exchange, and electrowinning). ${ }^{184,203}$ Typically, they have a lower energy budget and also allow the recovery of $\mathrm{Al}$ and $\mathrm{Li}$, but they require batteries to be mechanically crushed before treatment and can generate a large volume of process effluent that must be disposed of or recycled. ${ }^{184}$ Most industrialized LIB recycling processes can only recover secondary raw materials, which are not suitable for direct reuse in new batteries. ${ }^{204}$ Direct recycling, where battery materials (e.g., electrodes) are recovered and reintroduced into the manufacturing process with little additional processing methods, has been demonstrated at laboratory scale. This approach, which often employs supercritical $\mathrm{CO}_{2}$ to first remove the flammable electrolyte, can recover most battery materials. ${ }^{184}$

In 2016 , almost $95 \%$ of the spent batteries from consumer electronics products were landfilled. ${ }^{204}$ To add to this disposal load, in 2018 end-of-life LIBs from EVs are expected to start contributing to landfill. China alone will produce 2.5 billion used LIBs with a mass of about 500,000 metric tons by $2020 .^{200}$ Although disposing of LIBs in landfill can result in heavy metals and toxic electrolytes leaching into the groundwater ${ }^{202}$ and fires, ${ }^{204}$ to date, there has been limited environmental regulation and support from governments for collecting, sorting, and recycling spent LIBs. ${ }^{184}$ This situation is compounded by the fact that there is a large uncertainty regarding the cost of LIB recycling and hence the economic viability. If the cost of raw 
materials is less than the economically viable price for recycled materials, then there remains little incentive to recycle. To add to this situation, there is also uncertainty about the material composition of future LIBs. For example, if current efforts to reduce Co usage in batteries are successful, then the economic viability of recycling processes may be reduced even further. ${ }^{204}$ This uncertainty discourages development of highly specialized processes as they may become obsolete with material changes.

A number of recent reviews conclude that a regulatory driver may be necessary to develop and maintain a viable LIB recycling industry. ${ }^{184,205,206}$ Of particular concern is the treatment of spent LIBs, so that they are less hazardous to the environment. Current recycling processes, both pyrometallurgical and hydrometallurgical, can introduce additional environmental concerns (e.g., contaminated wastewater, gas effluent), and so further research is required to develop alternative recycling processes that do not introduce secondary pollution. ${ }^{202}$ Recycling could be especially beneficial to LIB manufacturers that lack an economic raw material supply. So, for example, to become a major LIB manufacturer, the United States may need to build new supply chain capabilities around recycled materials. ${ }^{184}$

\section{Conclusions and future perspectives}

High-rate LIBs can play a critical role in decarbonizing our energy systems both through their underpinning of the transition to use renewable energy resources and electrification of transport. In particular, they can play a key role in future flexible and resilient low-carbon electricity networks. PV is the fastest growing renewable energy technology, growing $40 \%$ per year over the last decade and having the fastest manufacturing experience rate of all renewable energy technologies. Because demand and generation are constantly varying with a high fraction of PV generators connected to the electricity grid, fast-reacting energy storage systems can be used to inject and withdraw power to stabilize electricity supply. The energy-power balance of currentgeneration LIBs suggests their suitability for this application; however, emerging material systems that can respond rapidly and have a long cycle life will be required for future grid-stabilization services to be provided at low cost.

Although high-rate LIBs require the design and engineering of battery modules and associated thermal and power management systems, rate performance and cycle life are ultimately limited by the materials used in cells and the kinetics associated with the charge transfer reactions and ionic and electronic transport. This review has summarized the technological strategies that can be used to enhance the rate capability of LIBs and, in particular, we reviewed the electrode and electrolyte material selection, electrode morphology, or structuring for enhanced electrolyte access to electrochemically active surfaces and electrode fabrication processes. Recent reports of high-rate electrodes are highlighting the need for advanced simulation models to predict ionic and electronic conduction though percolating materials and rates of charge transfer reactions to identify and address rate-limiting processes.

The linearly responsive capacitor-shaped discharge curves of new materials combined with high-rate charging and discharging can simplify integration with power electronics as the SoC is more easily determined. This is particularly relevant for integration with PV-generated power and may enable embedded distributed storage elements in electronic control systems. Finally, reduced battery cost will be critical for competitively priced PV-generated electricity. Manufacturing of high-rate LIBs for grid stabilization can directly build on the EV manufacturing experience for LIBs, and so costs are expected to approach material cost limits, which have been estimated to be in the order of US $\$ 100 / \mathrm{kWh}$. However, what is critical for grid stabilization is the service cost, and if alternative options for this service come at a high cost, then higher LIB costs may be tolerated here than for other battery applications. Recent reports suggest that LIBs are the only currently available energy storage technology able to provide support for the peaker, microgrid, and commercial (behind the meter) use cases, and this already competitive position can only be improved by LIBs with increased rate performance and perhaps more importantly increased cycle life.

\section{Supplementary material}

To view supplementary material for this article, please visit https://doi.org/10.1557/mre.2019.4.

\section{Acknowledgments}

This work has been supported by the Australian Research Council (ARC) through grants DP170103219 and FT170100447 (Future Fellowship-Alison Lennon). Yu Jiang and Charles Hall acknowledge the support of the Australian Government through their Research Training Program Scholarships. Kent J. Griffith acknowledges funding from the Winston Churchill Foundation of the United States and a Herchel Smith Scholarship. Kent J. Griffith and Clare P. Grey thank the EPSRC for a LIBATT grant (EP/M009521/1). The views expressed herein are not necessarily the views of the Australian Government, and the Australian Government does not accept responsibility for any information or advice contained herein.

\section{REFERENCES:}

1. Edison T.: Storage Batteries (New York, 1883). Available at: https:// archive.org/stream/pacruralpres25unse/pacruralpres25unse_djvu.txt (accessed October 22, 2018).

2. Tsao J.Y., Schubert E.F., Fouquet R., and Lave M.: The electrification of energy: Long-term trends and opportunities. MRS Energy Sustain. 5, E7 (2018).

3. Michalek J.J., Chester M., Jaramillo P., Samaras C., Shiau C.-S.N., and Lave L.B.: Valuation of plug-in vehicle life-cycle air emissions and oil displacement benefits. Proc. Natl. Acad. Sci. U. S. A. 108(40), 16554-16558 (2011).

4. Traut E., Hendrickson C., Klampfl E., Liu Y., and Michalek J.J.: Optimal design and allocation of electrified vehicles and dedicated charging infrastructure for minimum life cycle greenhouse gas emissions and cost. Energy Policy 51, 524-534 (2012).

5. IRENA: Electricity Storage and Renewables: Costs and Markets to (2030). Available at: http://www.irena.org (accessed July 1, 2018).

6. IRENA: Renewable Energy Statistics. Available at: http://www.irena.org/-/ media/Files/IRENA/Agency/Publication/2018/Jul/IRENA_Renewable_ Energy_Statistics_2018.pdf (accessed March 8, 2019).

7. Creutzig F., Agoston P., Goldschmidt J.C., Luderer G., Nemet G., and Pietzcker R.C.: The underestimated potential of solar energy to mitigate climate change. Nat. Energy 2, 17140 (2017). 
8. ITRPV: International Technology Roadmap for Photovoltaic Results (2017). Available at: http://www.itrpv.net/Reports/Downloads/ (accessed October 6, 2018).

9. Jacobson M.Z., Delucchi M.A., Bazouin G., Bauer Z.A.F., Heavey C.C., Fisher E., Morris S.B., Piekutowski D.J.Y., Vencill T.A., and Yeskoo T.W.: $100 \%$ clean and renewable wind, water, and sunlight all-sector energy roadmaps for 139 countries of the world. Joule 1(1), 108-121 (2017).

10. Clack C.T.M., Qvist S.A., Apt J., Bazilian M., Brandt A.R., Caldeira K., Davis S.J., Diakov V., Handschy M.A., Hines P.D.H., Jaramillo P., Kammen D.M., Long J.C.S., Granger Morgan M., Reed A., Sivaram V., Sweeney J., Tynan G.R., Victor D.G., Weyant J.P., and Whitacre J.F.: Evaluation of a proposal for reliable low-cost grid power with $100 \%$ wind, water, and solar. Proc. Natl. Acad. Sci. U. S. A. 114(26), 6722-6727 (2017).

11. Rogelj J., Popp A., Calvin K.V., Luderer G., Emmerling J., Gernaat D., Fujimori S., Strefler J., Hasegawa T., Marangoni G., Krey V., Kriegler E., Riahi K., van Vuuren D.P., Doelman J., Drouet L., Edmonds J., Fricko O., Harmsen M., Havlík P., Humpenöder F., Stehfest E., and Tavoni M.: Scenarios towards limiting global mean temperature increase below $1.5^{\circ} \mathrm{C}$. Nat. Clim. Change 8(4), 325-332 (2018).

12. Jones-Albertus R., Cole W., Denholm P., Feldman D., Woodhouse M., and Margolis R.: Solar on the rise: How cost declines and grid integration shape solar's growth potential in the United States. MRS Energy Sustain. 5, E4 (2018).

13. Babrowski S., Heinrichs H., Jochem P., and Fichtner W.: Load shift potential of electric vehicles in Europe. J. Power Sources 255, 283-293 (2014).

14. López M.A., de la Torre S., Martín S., and Aguado J.A.: Demand-side management in smart grid operation considering electric vehicles load shifting and vehicle-to-grid support. Int. J. Electr. Power Energy Syst. 64, 689-698 (2015)

15. Aziz M., Oda T., Mitani T., Watanabe Y., and Kashiwagi T.: Utilization of electric vehicles and their used batteries for peak-load shifting. Energies $8(5), 3720$ (2015)

16. Gnann T., Klingler A.-L., and Kühnbach M.: The load shift potential of plug-in electric vehicles with different amounts of charging infrastructure. J. Power Sources 390, 20-29 (2018).

17. Byrne R.H., Nguyen T.A., Copp D.A., Chalamala B.R., and Gyuk I.: Energy management and optimization methods for grid energy storage systems. IEEE Access 6, 13231-13260 (2018).

18. Marcos J., Marroyo L., Lorenzo E., Alvira D., and Izco E.: Power output fluctuations in large scale pv plants: One year observations with one second resolution and a derived analytic model. Prog. Photovoltaics Res. Appl. 19(2), 218-227 (2011).

19. Pourmousavi S.A., Cifala A.S., and Nehrir M.H.: Impact of high penetration of $\mathrm{PV}$ generation on frequency and voltage in a distribution feeder. In Proceedings of the 2012 North American Power Symposium (NAPS) (IEEE, 2012); pp. 1-8.

20. Shah R., Mithulananthan N., Bansal R.C., and Ramachandaramurthy V.K.: A review of key power system stability challenges for large-scale PV integration. Renewable Sustainable Energy Rev. 41, 1423-1436 (2015).

21. Anvari M., Lohmann G., Wächter M., Milan P., Lorenz E., Heinemann D. Tabar M.R.R., and Joachim P.: Short term fluctuations of wind and solar power systems. New J. Phys. 18(6), 063027 (2016).

22. Jiang Y., Fletcher J., Burr P., Hall C., Zheng B., Wang D.-W., Ouyang Z., and Lennon A.: Suitability of representative electrochemical energy storage technologies for ramp-rate control of photovoltaic power. J. Power Sources 384, 396-407 (2018).

23. Kroposki B., Johnson B., Zhang Y., Gevorgian V., Denholm P., Hodge B., and Hannegan B.: Achieving a 100\% renewable grid: Operating electric power systems with extremely high levels of variable renewable energy. IEEE Power Energy Mag. 15(2), 61-73 (2017).

24. Serban I. and Ion C.P.: Microgrid control based on a grid-forming inverter operating as virtual synchronous generator with enhanced dynamic response capability. Int. J. Electr. Power Energy Syst. 89, 94-105 (2017).

25. Denis G., Prevost T., Debry M., Xavier F., Guillaud X., and Menze A.: The migrate project: The challenges of operating a transmission grid with only inverter-based generation. A grid-forming control improvement with transient current-limiting control. IET Renew. Power Gener. 12(5), 523-529 (2018).
26. Chunsheng W., Hua L., Zilong Y., Yibo W., and Honghua X.: Voltage and frequency control of inverters connected in parallel forming a micro-grid. In Proceedings of the 2010 International Conference on Power System Technology (IEEE, 2010); pp. 1-6.

27. Carrasco J.M., Franquelo L.G., Bialasiewicz J.T., Galvan E. PortilloGuisado R.C., Prats M.A.M., Leon J.I., and Moreno-Alfonso N.: Power-electronic systems for the grid integration of renewable energy sources: A survey. IEEE Trans. Ind. Electron. 53(4), 1002-1016 (2006).

28. Marcos J., Marroyo L., Lorenzo E., and García M.: Smoothing of PV power fluctuations by geographical dispersion. Prog. Photovoltaics Res. Appl. 20(2), 226-237 (2012).

29. Delille G., Francois B., and Malarange G.: Dynamic frequency control support by energy storage to reduce the impact of wind and solar generation on isolated power system's inertia. IEEE Trans. Sustain. Energy 3(4), 931-939 (2012).

30. Swierczynski M., Stroe D.I., Stan A.I., Teodorescu R., and Sauer D.U.: Selection and performance-degradation modeling of $\mathrm{LiMO}_{2} / \mathrm{Li}_{4} \mathrm{Ti}_{5} \mathrm{O}_{12}$ and $\mathrm{LiFePO}_{4} / \mathrm{C}$ battery cells as suitable energy storage systems for grid integration with wind power plants: An example for the primary frequency regulation service. IEEE Trans. Sustain. Energy 5(1), 90-101 (2014).

31. Marcos J., Storkël O., Marroyo L., Garcia M., and Lorenzo E.: Storage requirements for PV power ramp-rate control. Sol. Energy 99, 28-35 (2014).

32. Schnabel J. and Valkealahti S.: Energy storage requirements for PV power ramp rate control in northern Europe. Int. J. Photoenergy 2016, 11 (2016).

33. Greenwood D.M., Lim K.Y., Patsios C., Lyons P.F., Lim Y.S., and Taylor P.C. Frequency response services designed for energy storage. Appl. Energy 203 115-127 (2017).

34. Nishi Y.: The development of lithium ion secondary batteries. Chem. Rec. 1(5), 406-413 (2001).

35. Goodenough J.B. and Park K.-S.: The Li-ion rechargeable battery: A perspective. J. Am. Chem. Soc. 135(4), 1167-1176 (2013).

36. Blomgren G.E.: The development and future of lithium ion batteries. J. Electrochem. Soc. 164(1), A5019-A5025 (2017).

37. Dunn B., Kamath H., and Tarascon J.-M.: Electrical energy storage for the grid: A battery of choices. Science 334(6058), 928-935 (2011).

38. Zaghib K., Mauger A., Groult H., Goodenough J., and Julien C.: Advanced electrodes for high power Li-ion batteries. Materials 6(3), 1028 (2013).

39. Thorbergsson E., Knap V., Swierczynski M., Stroe D., and Teodorescu R.: Primary frequency regulation with Li-ion battery based energy storage system-Evaluation and comparison of different control strategies. In Proceedings of the 35th International Telecommunications Energy Conference (IEEE, 2013); pp. 1-6.

40. Hesse H., Schimpe M., Kucevic D., and Jossen A.: Lithium-ion battery storage for the grid-A review of stationary battery storage system design tailored for applications in modern power grids. Energies 10(12), 2107 (2017).

41. ARPA-E: Duration Addition to Electricity Storage (DAYS): Technical Overview Document. Available at: https://arpa-e.energy.gov/sites/ default/files/documents/files/DAYS_ProgramOverview_FINAL.pdf (accessed March 8, 2019).

42. Sbordone D., Bertini I., Di Pietra B., Falvo M.C., Genovese A., and Martirano L.: EV fast charging stations and energy storage technologies: A real implementation in the smart micro grid paradigm. Electr. Power Syst. Res. 120, 96-108 (2015).

43. Armand M.B.: Intercalation electrodes. In Materials for Advanced Batteries, Murphy D., ed. (Springer US, Boston, Massachusetts, 1980); pp. 145-161.

44. Janek J. and Zeier W.G.: A solid future for battery development. Nat. Energy 1,16141 (2016).

45. Quinn J.B., Waldmann T., Richter K., Kasper M., and Wohlfahrt-Mehrens M.: Energy density of cylindrical Li-ion cells: A comparison of commercial 18650 to the 21700 cells. J. Electrochem. Soc. 165(14), A3284-A3291 (2018)

46. An S.J., Li J., Daniel C., Mohanty D., Nagpure S., and Wood D.L.: The state of understanding of the lithium-ion-battery graphite solid electrolyte interphase (SEI) and its relationship to formation cycling. Carbon 105 52-76 (2016).

47. Peled E. and Menkin S.: Review-SEI: Past, present and future. J. Electrochem. Soc. 164(7), A1703-A1719 (2017). 
48. Wang A., Kadam S., Li H., Shi S., and Qi Y.: Review on modeling of the anode solid electrolyte interphase (SEI) for lithium-ion batteries. npj Comput. Mater. 4(1), 15 (2018).

49. Somerville L., Bareño J., Trask S., Jennings P., McGordon A., Lyness C., and Bloom I.: The effect of charging rate on the graphite electrode of commercial lithium-ion cells: A post-mortem study. J. Power Sources 335, 189-196 (2016).

50. Vetter J., Novák P., Wagner M.R., Veit C., Möller K.C., Besenhard J.O., Winter M., Wohlfahrt-Mehrens M., Vogler C., and Hammouche A.: Ageing mechanisms in lithium-ion batteries. J. Power Sources 147(1), 269-281 (2005).

51. Zhao K., Pharr M., Vlassak J.J., and Suoa Z.: Fracture of electrodes in lithium-ion batteries caused by fast charging. J. Appl. Phys. 108(7), 073517 (2010).

52. Wen J., Yu Y., and Chen C.: A review on lithium-ion batteries safety issues: Existing problems and possible solutions. Mater. Express 2(3), 197-212 (2012).

53. Downie L.E., Krause L.J., Burns J.C., Jensen L.D., Chevrier V.L., and Dahn J.R.: In situ detection of lithium plating on graphite electrodes by electrochemical calorimetry. J. Electrochem. Soc. 160(4), A588-A594 (2013).

54. Deng D.: Li-ion batteries: Basics, progress, and challenges. Energy Sci. Eng. 3(5), 385-418 (2015).

55. Liu K., Liu Y., Lin D., Pei A., and Cui Y.: Materials for lithium-ion battery safety. Sci. Adv. 4(6), eaas9820 (2018).

56. Takami N., Satoh A., Hara M., and Ohsaki T.: Structural and kinetic characterization of lithium intercalation into carbon anodes for secondary lithium batteries. J. Electrochem. Soc. 142(2), 371-379 (1995).

57. Levi M.D. and Aurbach D.: Diffusion coefficients of lithium ions during intercalation into graphite derived from the simultaneous measurements and modeling of electrochemical impedance and potentiostatic intermittent titration characteristics of thin graphite electrodes. J. Phys. Chem. B 101(23), 4641-4647 (1997).

58. Kaskhedikar N.A. and Maier J.: Lithium storage in carbon nanostructures. Adv. Mater. 21(25-26), 2664-2680 (2009).

59. Nitta N., Wu F., Lee J.T., and Yushin G.: Li-ion battery materials: Present and future. Mater. Today 18(5), 252-264 (2015).

60. Schipper F., Erickson E.M., Erk C., Shin J.-Y., Chesneau F.F., and Aurbach D.: Review-Recent advances and remaining challenges for lithium ion battery cathodes: I. Nickel-rich, $\mathrm{LiNi}_{x} \mathrm{Co}_{y} \mathrm{Mn}_{z} \mathrm{O}_{2}$. J. Electrochem. Soc. 164(1), A6220-A6228 (2017).

61. Tarascon J.M. and Armand M.: Issues and challenges facing rechargeable lithium batteries. Nature 414, 359 (2001).

62. Xu K.: Nonaqueous liquid electrolytes for lithium-based rechargeable batteries. Chem. Rev. 104(10), 4303-4418 (2004).

63. Eftekhari A.: Lithium-ion batteries with high rate capabilities. ACS Sustainable Chem. Eng. 5(4), 2799-2816 (2017).

64. Liu Q., Du C., Shen B., Zuo P., Cheng X., Ma Y., Yin G., and Gao Y.: Understanding undesirable anode lithium plating issues in lithium-ion batteries. RSC Adv. 6(91), 88683-88700 (2016).

65. Jansen A.N., Kahaian A.J., Kepler K.D., Nelson P.A., Amine K., Dees D.W., Vissers D.R., and Thackeray M.M.: Development of a high-power lithium-ion battery. J. Power Sources 81-82, 902-905 (1999).

66. Ferg E., Gummow R.J., de Kock A., and Thackeray M.M.: Spinel anodes for lithium-ion batteries. J. Electrochem. Soc. 141(11), L147-L150 (1994).

67. Colbow K.M., Dahn J.R., and Haering R.R.: Structure and electrochemistry of the spinel oxides $\mathrm{LiTi}_{2} \mathrm{O}_{4}$ and $\mathrm{Li}_{43} \mathrm{Ti}_{53} \mathrm{O}_{4}$. J. Power Sources 26(3), 397-402 (1989).

68. Ohzuku T., Ueda A., and Yamamoto N.: Zero-strain insertion material of $\mathrm{Li}\left[\mathrm{Li}_{1 / 3} \mathrm{Ti}_{5 / 3}\right] \mathrm{O}_{4}$ for rechargeable lithium cells. J. Electrochem. Soc. 142(5), 1431-1435 (1995).

69. Sandhya C.P., John B., and Gouri C.J.I.: Lithium titanate as anode material for lithium-ion cells: A review. Ionics 20(5), 601-620 (2014).

70. Yang Z., Choi D., Kerisit S., Rosso K.M., Wang D., Zhang J., Graff G., and Liu J.: Nanostructures and lithium electrochemical reactivity of lithium titanites and titanium oxides: A review. J. Power Sources 192(2), 588-598 (2009).
71. Madian M., Eychmüller A., and Giebeler L.: Current advances in $\mathrm{TiO}_{2}$-based nanostructure electrodes for high performance lithium ion batteries. Batteries 4(1), 7 (2018)

72. Wen C.J., Boukamp B.A., Huggins R.A., and Weppner W.: Thermodynamic and mass transport properties of "LiAl". J. Electrochem. Soc. 126(12), 2258-2266 (1979)

73. Takami N., Kosugi S., and Inagaki H.: New SCiB ${ }^{\text {TM }}$ high-safety rechargeable battery for HEV application. Toshiba Rev. 63(12), 54-57 (2008).

74. Takami N., Inagaki H., Kishi T., Harada Y., Fujita Y., and Hoshina K.: Electrochemical kinetics and safety of 2-volt class Li-ion battery system using lithium titanium oxide anode. J. Electrochem. Soc. 156(2), A128-A132 (2009).

75. Manev V. and John Shelburne J.: Method for preparing a lithium ion cell. U.S. Patent No. 8420264, April 16, 2013.

76. Toshiba: SCiB ${ }^{T M}$ Cells. Available at: https://www.scib.jp/en/product/cell. htm (accessed October 22, 2018).

77. Ge H., Li N., Li D., Dai C., and Wang D.: Study on the theoretical capacity of spinel lithium titanate induced by low-potential intercalation. J. Phys. Chem. C113(16), 6324-6326 (2009).

78. Wang C., Wang S., Tang L., He Y.-B., Gan L., Li J., Du H., Li B., Lin Z., and Kang F.: A robust strategy for crafting monodisperse $\mathrm{Li}_{4} \mathrm{Ti}_{5} \mathrm{O}_{12}$ nanospheres as superior rate anode for lithium ion batteries. Nano Energy 21, 133-144 (2016)

79. Odziomek M., Chaput F., Rutkowska A., Świerczek K., Olszewska D., Sitarz M., Lerouge F., and Parola S.: Hierarchically structured lithium titanate for ultrafast charging in long-life high capacity batteries. Nat. Commun. 8, 15636 (2017).

80. Marchand R., Brohan L., and Tournoux M.: $\mathrm{TiO}_{2}(\mathrm{~B})$ a new form of titanium dioxide and the potassium octatitanate $\mathrm{K}_{2} \mathrm{Ti}_{8} \mathrm{O}_{17}$. Mater. Res. Bull. 15 , 1129-1133 (1980).

81. Brumbarov J., Vivek J.P., Leonardi S., Valero-Vidal C., Portenkirchner E., and Kunze-Liebhäuser J.: Oxygen deficient, carbon coated self-organized $\mathrm{TiO}_{2}$ nanotubes as anode material for Li-ion intercalation. J. Mater. Chem. A 3(32), 16469-16477 (2015).

82. Auer A., Steiner D., Portenkirchner E., and Kunze-Liebhäuser J.: Nonequilibrium phase transitions in amorphous and anatase $\mathrm{TiO}_{2}$ nanotubes. ACS Appl. Energy Mater. 1(5), 1924-1929 (2018).

83. Zukalová M., Kalbáč M., Kavan L., Exnar I., and Graetzel M. Pseudocapacitive lithium storage in $\mathrm{TiO}_{2}(\mathrm{~B})$. Chem. Mater. 17(5), 1248-1255 (2005).

84. Ren Y., Liu Z., Pourpoint F., Armstrong A.R., Grey C.P., and Bruce P.G.: Nanoparticulate $\mathrm{TiO}_{2}(\mathrm{~B})$ : An anode for lithium-ion batteries. Angew. Chem. 51(9), 2164-2167 (2012).

85. Arrouvel C., Parker S.C., and Islam M.S.: Lithium insertion and transport in the $\mathrm{TiO}_{2}-\mathrm{B}$ anode material: A computational study. Chem. Mater. 21(20), 4778-4783 (2009)

86. Dalton A.S., Belak A.A., and Van der Ven A.: Thermodynamics of lithium in $\mathrm{TiO}_{2}$ (B) from first principles. Chem. Mater. 24(9), 1568-1574 (2012).

87. Tian B., Xiang H., Zhang L., Li Z., and Wang H.: Niobium doped lithium titanate as a high rate anode material for Li-ion batteries. Electrochim. Acta 55(19), 5453-5458 (2010).

88. Han J.-T., Huang Y.-H., and Goodenough J.B.: New anode framework for rechargeable lithium batteries. Chem. Mater. 23(8), 2027-2029 (2011).

89. Anh L.T., Rai A.K., Thi T.V., Gim J., Kim S., Shin E.-C., Lee J.-S., and Kim J.: Improving the electrochemical performance of anatase titanium dioxide by vanadium doping as an anode material for lithium-ion batteries J. Power Sources 243, 891-898 (2013).

90. Lin C., Wang G., Lin S., Li J., and Lu L.: TiNb $6 \mathrm{O}_{17}$ : A new electrode material for lithium-ion batteries. Chem. Commun. 51(43), 8970-8973 (2015).

91. Lee Y.-S. and Ryu K.-S.: Study of the lithium diffusion properties and high rate performance of $\mathrm{TiNb}_{6} \mathrm{O}_{17}$ as an anode in lithium secondary battery. Sci. Rep. 7(1), 16617 (2017).

92. Griffith K.J., Senyshyn A., and Grey C.P.: Structural stability from crystallographic shear in $\mathrm{TiO}_{2}-\mathrm{Nb}_{2} \mathrm{O}_{5}$ phases: Cation ordering and lithiation behavior of $\mathrm{TiNb}_{24} \mathrm{O}_{62}$. Inorg. Chem. 56(7), 4002-4010 (2017).

93. Takami N., Ise K., Harada Y., Iwasaki T., Kishi T., and Hoshina K. High-energy, fast-charging, long-life lithium-ion batteries using $\mathrm{TiNb}_{2} \mathrm{O}_{7}$ anodes for automotive applications. J. Power Sources 396, 429-436 (2018). 
94. Wu X., Miao J., Han W., Hu Y.-S., Chen D., Lee J.-S., Kim J., and Chen L.: Investigation on $\mathrm{Ti}_{2} \mathrm{Nb}_{10} \mathrm{O}_{29}$ anode material for lithium-ion batteries. Electrochem. Commun. 25, 39-42 (2012).

95. Griffith K.J., Wiaderek K.M., Cibin G., Marbella L.E., and Grey C.P.: Niobium tungsten oxides for high-rate lithium-ion energy storage. Nature 559(7715), 556-563 (2018).

96. Daramalla V., Venkatesh G., Kishore B., Munichandraiah N., and Krupanidhi S.B.: Superior electrochemical performance of amorphous titanium niobium oxide thin films for Li-ion thin film batteries. J. Electrochem. Soc. 165(5), A764-A772 (2018).

97. Wohlfahrt-Mehrens M., Vogler C., and Garche J.: Aging mechanisms of lithium cathode materials. J. Power Sources 127(1), 58-64 (2004).

98. Padhi A.K., Nanjundaswamy K.S., and Goodenough J.B.: Phospho-olivines as positive-electrode materials for rechargeable lithium batteries. J. Electrochem. Soc. 144(4), 1188-1194 (1997).

99. Kang B. and Ceder G.: Battery materials for ultrafast charging and discharging. Nature 458(7235), 190-193 (2009).

100. Morgan D., Van der Ven A., and Ceder G.: Li conductivity in $\mathrm{Li}_{x} \mathrm{MPO}_{4}$ $(\mathrm{M}=\mathrm{Mn}, \mathrm{Fe}, \mathrm{Co}, \mathrm{Ni})$ olivine materials. Electrochem. Solid-State Lett. 7(2), A30-A32 (2004).

101. Islam M.S., Driscoll D.J., Fisher C.A.J., and Slater P.R.: Atomic-scale investigation of defects, dopants, and lithium transport in the $\mathrm{LiFePO}_{4}$ olivine-type battery material. Chem. Mater. 17(20), 5085-5092 (2005).

102. Ravet N., Chouinard Y., Magnan J.F., Besner S., Gauthier M., and Armand M.: Electroactivity of natural and synthetic triphylite. J. Power Sources 97-98, 503-507 (2001).

103. Doeff M.M., Hu Y., McLarnon F., and Kostecki R.: Effect of surface carbon structure on the electrochemical performance of $\mathrm{LiFePO}_{4}$. Electrochem. Solid-State Lett. 6(10), A207-A209 (2003).

104. Herle P.S., Ellis B., Coombs N., and Nazar L.F.: Nano-network electronic conduction in iron and nickel olivine phosphates. Nat. Mater. 3, 147 (2004).

105. Bai P., Cogswell D.A., and Bazant M.Z.: Suppression of phase separation in $\mathrm{LiFePO}_{4}$ nanoparticles during battery discharge. Nano Lett. 11(11), 4890-4896 (2011).

106. Malik R., Zhou F., and Ceder G.: Kinetics of non-equilibrium lithium incorporation in $\mathrm{LiFePO}_{4}$. Nat. Mater. 10, 587 (2011).

107. Wagemaker M., Singh D.P., Borghols W.J.H., Lafont U., Haverkate L., Peterson V.K., and Mulder F.M.: Dynamic solubility limits in nanosized olivine $\mathrm{LiFePO}_{4}$. J. Am. Chem. Soc. 133(26), 10222-10228 (2011).

108. Liu H., Strobridge F.C., Borkiewicz O.J., Wiaderek K.M., Chapman K.W., Chupas P.J., and Grey C.P.: Capturing metastable structures during high-rate cycling of $\mathrm{LiFePO}_{4}$ nanoparticle electrodes. Science 344(6191), 1252817 (2014).

109. Aricò A.S., Bruce P., Scrosati B., Tarascon J.-M., and van Schalkwijk W.: Nanostructured materials for advanced energy conversion and storage devices. Nat. Mater. 4, 366 (2005).

110. Bandaru P.R., Yamada H., Narayanan R., and Hoefer M.: Charge transfer and storage in nanostructures. Mater. Sci. Eng., R 96, 1-69 (2015).

111. Bae C.-J., Erdonmez C.K., Halloran J.W., and Chiang Y.-M.: Design of battery electrodes with dual-scale porosity to minimize tortuosity and maximize performance. Adv. Mater. 25(9), 1254-1258 (2013).

112. Habedank J.B., Kraft L., Rheinfeld A., Krezdorn C., Jossen A., and Zaeh M.F.: Increasing the discharge rate capability of lithium-ion cells with laser-structured graphite anodes: Modeling and simulation. J. Electrochem. Soc. 165(7), A1563-A1573 (2018).

113. Mangang M., Seifert H.J., and Pfleging W.: Influence of laser pulse duration on the electrochemical performance of laser structured $\mathrm{LiFePO}_{4}$ composite electrodes. J. Power Sources 304, 24-32 (2016).

114. Petkovich N.D. and Stein A.: Controlling macro- and mesostructures with hierarchical porosity through combined hard and soft templating. Chem. Soc. Rev. 42(9), 3721-3739 (2013).

115. Osiak M., Geaney H., Armstrong E., and O’Dwyer C.: Structuring materials for lithium-ion batteries: Advancements in nanomaterial structure, composition, and defined assembly on cell performance. J. Mater. Chem. A 2(25), 9433-9460 (2014).

116. Sakamoto J.S. and Dunn B.: Hierarchical battery electrodes based on inverted opal structures. J. Mater. Chem. 12(10), 2859-2861 (2002).
117. Li W., Liu J., and Zhao D.: Mesoporous materials for energy conversion and storage devices. Nat. Rev. Mater. 1, 16023 (2016).

118. Delattre B., Amin R., Sander J., De Coninck J., Tomsia A.P., and Chiang Y.-M.: Impact of pore tortuosity on electrode kinetics in lithium battery electrodes: Study in directionally freeze-cast $\mathrm{LiNi}_{0.8} \mathrm{Co}_{0 \cdot 15} \mathrm{Al}_{0.05} \mathrm{O}_{2}$ (NCA). J. Electrochem. Soc. 165(2), A388-A395 (2018).

119. Guo Y.-G., Hu J.-S., and Wan L.-J.: Nanostructured materials for electrochemical energy conversion and storage devices. Adv. Mater. 20(15), 2878-2887 (2008).

120. Bruce P.G., Scrosati B., and Tarascon J.-M.: Nanomaterials for rechargeable lithium batteries. Angew. Chem., Int. Ed. 47(16), 2930-2946 (2008).

121. Sun Y.-K., Chen Z., Noh H.-J., Lee D.-J., Jung H.-G., Ren Y., Wang S., Yoon C.S., Myung S.-T., and Amine K.: Nanostructured high-energy cathode materials for advanced lithium batteries. Nat. Mater. 11, 942 (2012).

122. Wu H.B., Chen J.S., Hng H.H., and Wen Lou X.: Nanostructured metal oxide-based materials as advanced anodes for lithium-ion batteries. Nanoscale 4(8), 2526-2542 (2012).

123. Lee K., Mazare A., and Schmuki P.: One-dimensional titanium dioxide nanomaterials: Nanotubes. Chem. Rev. 114(19), 9385-9454 (2014).

124. Zhang J. and Yu A.: Nanostructured transition metal oxides as advanced anodes for lithium-ion batteries. Sci. Bull. 60(9), 823-838 (2015).

125. Palacin M.R., Simon P., and Tarascon J.M.: Nanomaterials for electrochemical energy storage: The good and the bad. Acta Chim. Slov. 63(3), 7 (2016).

126. Li X. and Sun X.: Nanostructured materials for Li-ion batteries and beyond. Nanomaterials 6(4), 63 (2016).

127. Zhang X., Porras-Gutierrez A.-G., Mauger A., Groult H., and Julien C.: Nanotechnology of positive electrodes for Li-ion batteries. Inorganics $5(2)$, 25 (2017).

128. Obrovac M.N. and Dahn J.R.: Implications of finite-size and surface effects on nanosize intercalation materials. Phys. Rev. B 61(10), 6713-6719 (2000).

129. Delmer O., Balaya P., Kienle L., and Maier J.: Enhanced potential of amorphous electrode materials: Case study of $\mathrm{RuO}_{2}$. Adv. Mater. 20(3), 501-505 (2008).

130. Pean C., Daffos B., Rotenberg B., Levitz P., Haefele M., Taberna P.-L., Simon P., and Salanne M.: Confinement, desolvation, and electrosorption effects on the diffusion of ions in nanoporous carbon electrodes. J. Am. Chem. Soc. 137(39), 12627-12632 (2015).

131. Kondrat S. and Kornyshev A.A.: Pressing a spring: What does it take to maximize the energy storage in nanoporous supercapacitors? Nanoscale Horiz. 1(1), 45-52 (2016)

132. Fichtner M.: Nanoconfinement effects in energy storage materials. Phys. Chem. Chem. Phys. 13(48), 21186-21195 (2011).

133. Salanne M., Rotenberg B., Naoi K., Kaneko K., Taberna P.L., Grey C.P., Dunn B., and Simon P.: Efficient storage mechanisms for building better supercapacitors. Nat. Energy 1, 16070 (2016).

134. Augustyn V. and Gogotsi Y.: 2D materials with nanoconfined fluids for electrochemical energy storage. Joule 1(3), 443-452 (2017).

135. Prehal C., Koczwara C., Jäckel N., Schreiber A., Burian M., Amenitsch H., Hartmann M.A., Presser V., and Paris O.: Quantification of ion confinement and desolvation in nanoporous carbon supercapacitors with modelling and in situ X-ray scattering. Nat. Energy 2, 16215 (2017).

136. Yue Y. and Liang H.: 3D current collectors for lithium-ion batteries: A topical review. Small Methods 2(8), 1800056 (2018).

137. Wang Y.-Q., Gu L., Guo Y.-G., Li H., He X.-Q., Tsukimoto S., Ikuhara Y., and Wan L.-J.: Rutile-TiO 2 nanocoating for a high-rate $\mathrm{Li}_{4} \mathrm{Ti}_{5} \mathrm{O}_{12}$ anode of a lithium-ion battery. J. Am. Chem. Soc. 134(18), 7874-7879 (2012).

138. Lu X., Gu L., Hu Y.-S., Chiu H.-C., Li H., Demopoulos G.P., and Chen L.: New insight into the atomic-scale bulk and surface structure evolution of $\mathrm{Li}_{4} \mathrm{Ti}_{5} \mathrm{O}_{12}$ anode. J. Am. Chem. Soc. 137(4), 1581-1586 (2015).

139. Wang L., Liang K., Wang G., and Yang Y.: Interface-engineered hematite nanocones as binder-free electrodes for high-performance lithium-ion batteries. J. Mater. Chem. A 6(28), 13968-13974 (2018).

140. Choi H., Park H., Um J.H., Yoon W.-S., and Choe H.: Processing and characterization of titanium dioxide grown on titanium foam for potential use as Li-ion electrode. Appl. Surf. Sci. 411, 363-367 (2017).

141. Cui Y. and Zhang H.: Synthesis of $\mathrm{MoO}_{2}$ and nitrogen-doped carbon nanotubes composite materials by electrodeposition as binder-free electrode for lithium-ion batteries. In ECS Meeting Abstracts MA201502(8) (The Electrochemical Society, 2015); p. 542. 
142. Ji H., Zhang L., Pettes M.T., Li H., Chen S., Shi L., Piner R., and Ruoff R.S. Ultrathin graphite foam: A three-dimensional conductive network for battery electrodes. Nano Lett. 12(5), 2446-2451 (2012).

143. Yao M., Okuno K., Iwaki T., Awazu T., and Sakai T.: Long cycle-life $\mathrm{LiFePO}_{4} / \mathrm{Cu}-\mathrm{Sn}$ lithium ion battery using foam-type three-dimensional current collector. J. Power Sources 195(7), 2077-2081 (2010).

144. Bi Z., Paranthaman M.P., Menchhofer P.A., Dehoff R.R., Bridges C.A., Chi M., Guo B., Sun X.-G., and Dai S.: Self-organized amorphous $\mathrm{TiO}_{2}$ nanotube arrays on porous Ti foam for rechargeable lithium and sodium ion batteries. J. Power Sources 222, 461-466 (2013).

145. Jiang Y., Hall C., Song N., Lau D., Burr P., Patterson R., Wang D.-W., Ouyang Z., and Lennon A.: Evidence for fast lithium-ion diffusion and charge transfer reactions in amorphous TiOx nanotubes: Insights for high rate electrochemical energy storage. ACS Appl. Mater. Interfaces 10(49), 42513-42523 (2018).

146. Yoo M., Frank C.W., Mori S., and Yamaguchi S.: Effect of poly(vinylidene fluoride) binder crystallinity and graphite structure on the mechanical strength of the composite anode in a lithium ion battery. Polymer 44(15), 4197-4204 (2003).

147. Bülter H., Peters F., Schwenzel J., and Wittstock G.: In situ quantification of the swelling of graphite composite electrodes by scanning electrochemical microscopy. J. Electrochem. Soc. 163(2), A27-A34 (2016).

148. Zhang X., Cheng X., and Zhang Q.: Nanostructured energy materials for electrochemical energy conversion and storage: A review. J. Energy Chem. 25, 967-984 (2016).

149. Logan E.R., Tonita E.M., Gering K.L., Li J., Ma X., Beaulieu L.Y., and Dahn J.R.: A study of the physical properties of Li-ion battery electrolytes containing esters. J. Electrochem. Soc. 165(2), A21-A30 (2018).

150. Nishi Y., Azuma H., and Omaru A.: Non aqueous electrolyte cell. U.S. Patent No. 4959281, 1990.

151. Valøen L.O. and Reimers J.N.: Transport properties of $\mathrm{LiPF}_{6}$-based li-ion battery electrolytes. J. Electrochem. Soc. 152(5), A882-A891 (2005).

152. Pavlov D., Naidenov V., and Ruevski S.: Influence of $\mathrm{H}_{2} \mathrm{SO}_{4}$ concentration on lead-acid battery performance: H-type and P-type batteries. J. Power Sources 161(1), 658-665 (2006).

153. Doyle M., Fuller T.F., and Newman J.: The importance of the lithium ion transference number in lithium/polymer cells. Electrochim. Acta 39(13), 2073-2081 (1994)

154. Capiglia C., Saito Y., Kageyama H., Mustarelli P., Iwamoto T., Tabuchi T., and Tukamoto H.: $7 \mathrm{Li}$ and $19 \mathrm{~F}$ diffusion coefficients and thermal properties of non-aqueous electrolyte solutions for rechargeable lithium batteries. J. Power Sources 81-82, 859-862 (1999).

155. Diederichsen K.M., McShane E.J., and McCloskey B.D.: Promising routes to a high $\mathrm{Li}^{+}$transference number electrolyte for lithium ion batteries. ACS Energy Lett. 2(11), 2563-2575 (2017).

156. Buannic L., Colin J.-F., Chapuis M., Chakir M., and Patoux S.: Electrochemical performances and gassing behavior of high surface area titanium niobium oxides. J. Mater. Chem. A 4(29), 11531-11541 (2016).

157. Lv W., Gu J., Niu Y., Wen K., and He W.: Review-Gassing mechanism and suppressing solutions in $\mathrm{Li}_{4} \mathrm{Ti}_{5} \mathrm{O}_{12}$-based lithium-ion batteries. J. Electrochem. Soc. 164(9), A2213-A2224 (2017).

158. Rodrigues M.-T.F., Kalaga K., Trask S.E., Shkrob I.A., and Abraham D.P.: Anode-dependent impedance rise in layered-oxide cathodes of lithium-ion cells. J. Electrochem. Soc. 165(9), A1697-A1705 (2018).

159. Takenaka N., Suzuki Y., Sakai H., and Nagaoka M.: On electrolytedependent formation of solid electrolyte interphase film in lithium-ion batteries: Strong sensitivity to small structural difference of electrolyte molecules. J. Phys. Chem. C 118(20), 10874-10882 (2014).

160. Wang J., Yamada Y., Sodeyama K., Chiang C.H., Tateyama Y., and Yamada A.: Superconcentrated electrolytes for a high-voltage lithium-ion battery. Nat. Commun. 7, 12032 (2016).

161. Drozhzhin O.A., Shevchenko V.A., Zakharkin M.V., Gamzyukov P.I., Yashina L.V., Abakumov A.M., Stevenson K.J., and Antipov E.V.: Improving salt-to-solvent ratio to enable high-voltage electrolyte stability for advanced Li-ion batteries. Electrochim. Acta 263, 127-133 (2018).
162. Zeng Z., Murugesan V., Han K.S., Jiang X., Cao Y., Xiao L., Ai X., Yang H., Zhang J.-G., Sushko M.L., and Liu J.: Non-flammable electrolytes with high salt-to-solvent ratios for Li-ion and Li-metal batteries. Nat. Energy 3(8), 674-681 (2018).

163. Sloop S.E., Pugh J.K., Wang S., Kerr J.B., and Kinoshita K.: Chemical reactivity of $\mathrm{PF}_{5}$ and $\mathrm{LiPF}_{6}$ in ethylene carbonate/dimethyl carbonate solutions. Electrochem. Solid-State Lett. 4(4), A42-A44 (2001).

164. Zhang X. and Devine T.M.: Identity of passive film formed on aluminum in li-ion battery electrolytes with $\mathrm{LiPF}_{6}$. J. Electrochem. Soc. 153(9), B344-B351 (2006).

165. Aurbach D., Markovsky B., Levi M.D., Levi E., Schechter A., Moshkovich M., and Cohen Y.: New insights into the interactions between electrode materials and electrolyte solutions for advanced nonaqueous batteries. J. Power Sources 81-82, 95-111 (1999).

166. Kim J.-H., Pieczonka N.P.W., Li Z., Wu Y., Harris S., and Powell B.R.: Understanding the capacity fading mechanism in $\mathrm{LiNi}_{0.5} \mathrm{Mn}_{1.5} \mathrm{O}_{4} /$ graphite Li-ion batteries. Electrochim. Acta 90, 556-562 (2013).

167. Pieczonka N.P.W., Liu Z., Lu P., Olson K.L., Moote J., Powell B.R., and Kim J.-H.: Understanding transition-metal dissolution behavior in $\mathrm{LiNi}_{0.5} \mathrm{Mn}_{1.5} \mathrm{O}_{4}$ high-voltage spinel for lithium ion batteries. J. Phys. Chem. C117(31), 15947-15957 (2013).

168. Jiang F. and Peng P.: Elucidating the performance limitations of lithium-ion batteries due to species and charge transport through five characteristic parameters. Sci. Rep. 6, 32639 (2016).

169. Bai P. and Bazant M.Z.: Charge transfer kinetics at the solid-solid interface in porous electrodes. Nat. Commun. 5, 3585 (2014).

170. Yamada H. and Bandaru P.R.: Electrochemical kinetics and dimensional considerations, at the nanoscale. AIP Adv. 6(6), 065325 (2016).

171. Goubard-Bretesché N., Crosnier O., Favier F., and Brousse T.: Improving the volumetric energy density of supercapacitors. Electrochim. Acta 206, 458-463 (2016).

172. Miller J.R. and Burke A.K.: Electrochemical capacitors: Challenges and opportunities for real-world applications. Electrochem. Soc. Interface 17(1), 53057 (2008).

173. Gao S., Rahmat-Samii Y., Hodges R.E., and Yang X.: Advanced antennas for small satellites. Proc. IEEE 106(3), 391-403 (2018).

174. Schmidt O., Hawkes A., Gambhir A., and Staffell I.: The future cost of electrical energy storage based on experience rates. Nat. Energy 2, 17110 (2017).

175. Lazard: Levelized Cost of Storage Analysis (2016). Available at: https:// www.lazard.com/perspective/levelized-cost-of-storage-analysis-20/ (accessed September 5, 2018).

176. Lazard: Levelized Cost of Storage Analysis (2017). Available at: https:// www.lazard.com/perspective/levelized-cost-of-storage-2017/ (accessed September 5, 2018).

177. Meshram P., Pandey B.D., and Mankhand T.R.: Extraction of lithium from primary and secondary sources by pre-treatment, leaching and separation: A comprehensive review. Hydrometallurgy 150, 192-208 (2014).

178. Martin G., Rentsch L., Höck M., and Bertau M.: Lithium market research-Global supply, future demand and price development. Energy Storage Mater. 6, 171-179 (2017).

179. Perotti R. and Coviello M.F.: Governance of Strategic Minerals in Latin America: The Case of Lithium. Available at: https://repositorio.cepal.org/ bitstream/handle/11362/38961/S1500861_en.pdf (accessed July 1, 2017).

180. Jaskula B.W.: U.S. Geological Survey, Mineral Commodity Summaries (2018). Available at: https://minerals.usgs.gov/minerals/pubs/ commodity/lithium/mcs-2018-lithi.pdf (accessed October 22, 2018).

181. Loganathan P., Naidu G., and Vigneswaran S.: Mining valuable minerals from seawater: A critical review. Environ. Sci.: Water Res. Technol. 3(1), 37-53 (2017).

182. Paranthaman M.P., Li L., Luo J., Hoke T., Ucar H., Moyer B.A., and Harrison S.: Recovery of lithium from geothermal brine with lithium-aluminum layered double hydroxide chloride sorbents. Environ. Sci. Technol. 51(22), 13481-13486 (2017).

183. Li L., Deshmane V.G., Paranthaman M.P., Bhave R., Moyer B.A., and Harrison S.: Lithium recovery from aqueous resources and batteries: A brief review. Johnson Matthey Technol. Rev. 62(2), 161-176 (2018). 
184. Mayyas A., Steward D., and Mann M.: The case for recycling: Overview and challenges in the material supply chain for automotive li-ion batteries. Sustainable Mater. Technol. 19, e00087 (2019).

185. Narins T.P.: The battery business: Lithium availability and the growth of the global electric car industry. Extr. Ind. Soc. 4(2), 321-328 (2017).

186. Sanderson H.: Lithium Prices to Fall 45\% by 2021, Morgan Stanley Says. Available at: https://www.ft.com/content/66012fe2-1ae1-11e8-aaca4574d7dabfb6 (accessed July 1, 2018).

187. Kushnir D. and Sandén B.A.: The time dimension and lithium resource constraints for electric vehicles. Resour. Policy 37(1), 93-103 (2012).

188. Olivetti E.A., Ceder G., Gaustad G.G., and Fu X.: Lithium-ion battery supply chain considerations: Analysis of potential bottlenecks in critical metals. Joule 1(2), 229-243 (2017).

189. Charles R.G., Douglas P., Hallin I.L., Matthews I., and Liversage G.: An investigation of trends in precious metal and copper content of RAM modules in WEEE: Implications for long term recycling potential. Waste Manag. 60, 505-520 (2017).

190. Hertwich E.G., Gibon T., Bouman E.A., Arvesen A., Suh S., Heath G.A., Bergesen J.D., Ramirez A., Vega M.I., and Shi L.: Integrated life-cycle assessment of electricity-supply scenarios confirms global environmental benefit of low-carbon technologies. Proc. Natl. Acad. Sci. U. S. A. 112(20), 6277 (2015).

191. Energy Matters: Solar PV and Electric Vehicles to Boost Copper Demand (2016). Available at: https://www.energymatters.com.au/renewable-news/ solar-pv-copper-em5729/ (accessed September 7, 2018).

192. Ciacci L., Vassura I., and Passarini F.: Urban mines of copper: Size and potential for recycling in the EU. Resources 6(1), 6 (2017).

193. Graedel T.E., Allwood J., Birat J.-P., Buchert M., Hagelüken C., Reck B.K., Sibley S.F., and Sonnemann G.: What do we know about metal recycling rates? 15(3), 355-366 (2011).

194. Weight D.: Cobalt Production Statistics: 2017 Production Statistics. Available at: https://www.cobaltinstitute.org/statistics.html (accessed October 23, 2018).
195. Shedd K.B.: U.S. Geological Survey, Mineral Commodity Summaries (2018). Available at: https://minerals.usgs.gov/minerals/pubs/ commodity/cobalt/mcs-2018-cobal.pdf (accessed October 22, 2018).

196. King A.: Battery Builders Get the Cobalt Blues. Available at: https://www. chemistryworld.com/news/battery-builders-get-the-cobaltblues/3008738.article (accessed July 1, 2018).

197. Sanderson H.: China Tightens Grip on Global Cobalt Supplies. Available at: https://www.ft.com/content/86dc1306-27a4-11e8-b27e-cc62a39d57a0 (accessed July 1, 2018).

198. INN: The Critical Need for Cobalt Supply Diversification. Available at: https://investingnews.com/innspired/cobalt-drc-supply-chain-risk/ (accessed July 1, 2018).

199. Call2Recycle: Recycling Laws by State. Available at: https://www. call2recycle.org/recycling-laws-by-state/ (accessed March 8, 2019).

200. Zeng X., Li J., and Singh N.: Recycling of spent lithium-ion battery: A critical review. Crit. Rev. Environ. Sci. Technol. 44(10), 1129-1165 (2014).

201. Ordoñez J., Gago E.J., and Girard A.: Processes and technologies for the recycling and recovery of spent lithium-ion batteries. Renewable Sustainable Energy Rev. 60, 195-205 (2016).

202. Zheng X., Zhu Z., Lin X., Zhang Y., He Y., Cao H., and Sun Z.: A mini-review on metal recycling from spent lithium ion batteries. Engineering 4(3), 361-370 (2018).

203. Lv W., Wang Z., Cao H., Sun Y., Zhang Y., and Sun Z.: A critical review and analysis on the recycling of spent lithium-ion batteries. ACS Sustainable Chem. Eng. 6(2), 1504-1521 (2018).

204. Heelan J., Gratz E., Zheng Z., Wang Q., Chen M., Apelian D., and Wang Y.: Current and prospective li-ion battery recycling and recovery processes. JOM 68(10), 2632-2638 (2016).

205. Zeng X., Li J., and Liu L.: Solving spent lithium-ion battery problems in China: Opportunities and challenges. Renewable Sustainable Energy Rev. 52, 1759-1767 (2015).

206. Zhang W., Xu C., He W., Li G., and Huang J.: A review on management of spent lithium ion batteries and strategy for resource recycling of all components from them. Waste Manag. Res. 36(2), 99-112 (2018). 